\title{
Palladin, an actin-associated protein, is required for adherens junction formation and intercellular adhesion in HCT116 colorectal cancer cells
}

\author{
PUEI NAM TAY ${ }^{1}$, PATRICK TAN ${ }^{2}$, YUHONG LAN ${ }^{1}$, CAROL HO-WING LEUNG $^{1}$, MIRTHA LABAN ${ }^{1}$, \\ TZE CHIN TAN ${ }^{1}$, HONGMIN NI ${ }^{1}$, JAYAPAL MANIKANDAN ${ }^{1}$, SUHAIMI BIN ABDUL RASHID ${ }^{3}$, \\ BENEDICT YAN $^{3}$, CELESTIAL THERESE YAP ${ }^{1}$, LINA HSIU KIM LIM ${ }^{1}$, \\ YAW CHYN LIM ${ }^{1}$ and SHING CHUAN HOOI ${ }^{1}$ \\ ${ }^{1}$ Department of Physiology, Yong Loo Lin School of Medicine, National University of Singapore; \\ ${ }^{2}$ Duke-NUS Graduate Medical School; ${ }^{3}$ Department of Pathology, National University Hospital, Singapore
}

Received March 22, 2010; Accepted April 26, 2010

DOI: 10.3892/ijo_00000742

\begin{abstract}
Palladin is a scaffold protein involved in the formation of actin-associated protein complexes. Gene expression array analysis on the poorly metastatic HCT116 colon cancer cell line and a metastatic derivative cell line (E1) with EMT (epithelial-mesenchymal transition) features showed a down-regulation of palladin gene expression in the latter. Knockdown of palladin expression in the HCT116 cells suppressed junctional localization of E-cadherin, reduced intercellular adhesion and collective cell migration, showing that palladin plays an important role in maintaining the integrity of adherens junctions. The acquisition of the EMT features by the E1 cell line was dependent on the Erk pathway. Inhibition of this pathway by U0126 treatment in E1 cells resulted in the re-expression of palladin, relocalization of E-cadherin to the adherens junctions and a reversal of EMT features. The re-establishment of intercellular adhesion was dependent on palladin expression. The down-regulation of palladin was also observed in poorly-differentiated tumor tubules and dissociated tumor cells that have undergone de-differentiation in human primary colon tumors. Our data show that palladin is an integral component of adherens junctions and plays a role in the localization of E-cadherin to the junctions. The loss of palladin may be an integral part of EMT, an early step in the metastatic spread of colon carcinoma.
\end{abstract}

\section{Introduction}

Colorectal cancer is one of the most common and deadly cancers in developed countries, accounting for approximately

Correspondence to: Dr S.C. Hooi, Department of Physiology, Yong Loo Lin School of Medicine, National University of Singapore, Singapore

E-mail: shing_chuan_hooi@nuhs.edu.sg

Key words: palladin, adherens junction, epithelial-mesenchymal transition, metastasis, colorectal cancer
$8 \%$ of deaths from all cancers worldwide (1). Although surgical resection is highly effective for early stage tumors (with cure rates of over $90 \%$ in stage I and $75 \%$ in stage II disease), the treatment of advanced colon cancer with metastases remains essentially palliative, as these later stage malignancies respond poorly to current chemotherapeutic regimens (2). The genetic mechanisms underlying the adenoma-carcinoma progression in colon cancer are relatively well understood, and has been shown to involve the mutational activation of oncogenes (such as ras and $m y c$ ) and suppression of tumor suppressor genes (such as Apc and p53). In contrast, although the physiological steps of metastasis $(3,4)$ have been well-characterized, the molecular mechanisms for the progression from carcinoma in situ to invasive and metastatic tumors are less clear. An understanding of the molecular mechanisms involved in the acquisition of the metastatic phenotype will be required to provide more effective therapeutic targets and prognostic markers of colon cancer progression.

Gene profiling has been used extensively to understand the genetic basis of metastasis. Several gene profiling studies on colon cancer metastasis have been published and these included comparisons of gene expression profiles between metastatic and primary tumors or tumors with and without lymph node metastasis (5). However, the overlaps in the candidate gene lists generated by these different studies are limited, due to the diverse types of patient samples used, different array platforms, data analysis algorithms and specific biases involved in each study. Moreover, recent studies have highlighted the heterogeneity in the cell population within a tumor sample. One of the mechanisms implicated in the progression to invasion and metastasis in colon tumors appears to involve primarily cells at the invasive front. The cells at the invasive fronts were shown to exhibit alterations in epithelial structure and function, leading to a dissolution of adherens junctions, reorganization of the actin cytoskeleton, loss of apical-basal polarity, loss of epithelial markers, induction of a mesenchymal gene-expression program and enhanced motility and invasion: a process referred to as epithelialmesenchymal transition (EMT) (6-8). Hence, a global transcriptome analysis of whole tumor samples may obscure 
important genetic alterations that occur in the minority of cells within a tumor. An alternate strategy to identify genes associated with colon cancer metastasis, therefore, might be to compare gene expression profiles of cell lines with differing metastatic abilities. Studies have shown that nude mice may be used as 'cell sorters' to select for metastatic variants in xenograft models. This strategy was successfully used to identify genes that enhance lung metastasis by mouse melanoma cells (9), genes that promote metastasis to the bone in human breast cancers (10) and the transcription factor Twist in the promotion of EMT and metastasis in breast cancer cells (11).

To identify novel genetic changes important in colon cancer metastasis, we have characterized metastatic cell lines derived from a poorly metastatic human colon cancer cell line HCT116 using in vivo passaging in athymic nude mice. One of the metastatic cell lines, E1, exhibited features reminiscent of EMT with a mesenchymal/fibroblastic morphology, a loss of intercellular adhesion, increased invasiveness and increased metastatic potential compared to HCT116. The Erk signaling pathway, one of the important pathways involved in EMT (12) was also identified to be responsible for the EMT-like features of the E1 cells. However, the loss of intercellular adhesion in the E1 cells was not due to a reduction of E-cadherin expression. Instead, E-cadherin and components of the cadherin-catenin complex ( $\beta$-catenin, $\alpha$-catenin, $\alpha$-actinin, p120-catenin) were localized to the cytoplasm of the cells rather than adherens junctions. Gene expression array analysis on the E1 cell line in comparison to the parental HCT116 showed dysregulation of gene expression in known metastasis mediators such as S100A4, EMT-related genes or genes involved in intestinal epithelium development pathways such as BMP4, Jag1 Sox9, genes affecting chromatin structure/ transcription that has been shown to promote metastasis such as SATB1 as well as genes affecting cytoskeleton organization or cell adhesion such as PDLIM5, PALLD (palladin), DLG5, DSC2, PLEC1, ITGA6. In this study, we have identified palladin, an actin cross-linker and scaffold for the formation of actin-associated protein complexes, as a novel regulator of an EMT-like phenotype in metastatic colon cancer cells. Besides being able to bind to actin-associated proteins such as $\alpha$-actinin, VASP, profilin, ezrin and Eps8, palladin also interacts with signaling intermediaries such as ArgBP-2, SPIN-90 and Src (13). Palladin is detected in cytoskeletal structures that contain contractile bundles of actin filaments, such as stress fibers of non-muscle cells, and localizes to anchoring structures such as focal adhesions and motile structures such as dorsal ruffles (14-16). Hence, it has been suggested that palladin functions as an organizer to recruit molecules involved in actin assembly in cell adhesion and movement (13). Also, it is well established that both the formation and maintenance of adherens junctions in epithelial cells depend on the actin cytoskeleton (17). Proteins involved in the regulation of actin polymerization therefore have often been found to have crucial roles in the establishment of adherens junctions (17). An RNAi-mediated silencing approach was used to demonstrate that palladin is required for the integrity of adherens junctions. Knockdown of palladin suppresses the junctional localization of E-cadherin without a change in E-cadherin total expression and affects collective cell migration. Moreover, upon inhibition of the Erk pathway, which reversed the mesenchymal phenotype to that of epithelial, palladin was re-expressed and localized to the adherens junctions. The expression of palladin was also down-regulated in poorly-differentiated tumor tubules or dissociated tumor cells that have undergone dedifferentiation to adopt a more mesenchymal phenotype, compared to well-differentiated tumor cells. Our data show that palladin is an important component of adherens junctions and plays a role in maintaining the integrity of adherens junctions. The loss of palladin may be an early step in the metastatic spread of colon carcinoma.

\section{Materials and methods}

Cell culture and transfections. The human colon cancer cell line HCT116 was purchased from American Type Culture Collection (ATCC). The HCT116 cell line and its metastatic derivative E1 were cultured in McCoy's 5A modified medium (Sigma-Aldrich) supplemented with $10 \%$ fetal bovine serum (FBS) $\left(\right.$ Gibco $^{\circledR}$, Invitrogen $\left.{ }^{\mathrm{TM}}\right)$. Cells were grown as adherent cultures at $37^{\circ} \mathrm{C}$ in a humidified incubator supplemented with $5 \% \mathrm{CO}_{2}$. Palladin expression in HCT116 cells was silenced by transient transfection of Stealth ${ }^{\mathrm{TM}}$ RNAi targeted against palladin (Invitrogen) using Lipofectamine ${ }^{\mathrm{TM}}$ RNAiMAX reagent (Invitrogen). RNAi \#1 (5' gggcagcccttcaaatgcaatt caa 3') and RNAi \#4 (5' gccgtggagtaaat ggactgattaa 3') target only the $140 \mathrm{kDa}$ palladin isoform. RNAi \#2 (5' cagtgcggetg gaatgtcgtgtatt $3^{\prime}$ ) and RNAi \#3 (5' gctgacagtgcaactgtctttaata $\left.3^{\prime}\right)$ target both the 90 and $140 \mathrm{kDa}$ palladin isoforms. Transfected cells were usually re-seeded for other functional assays $24 \mathrm{~h}$ post-transfection. Medium GC Duplex (Invitrogen) was used as a negative control as the RNAi synthesized were of medium GC content (i.e., 45-55\% GC).

Cell aggregation assay. Adherent cells were detached by Cell Dissociation Buffer (Invitrogen) and dispersed by pipetting into single cell suspension. Ten thousand cells were added to each well of the 24-well ultra low cluster plates (Corning Costar) and cultured for $24 \mathrm{~h}$ in a tissue culture incubator, after which images were taken with a camera attached to the Zeiss Axiovert microscope equipped with a x10 phase-contrast objective. Three independent experiments were carried out in triplicates for each treatment condition.

In vitro invasion assay. $\mathrm{BD}$ Matrigel ${ }^{\mathrm{TM}}$ basement membrane matrix (BD Biosciences) was diluted 10-fold and coated on the upper chamber membrane (pore size $8.0 \mu \mathrm{m}$ ) in $6.5 \mathrm{~mm}$ diameter transwells (Corning Costar). Cells were harvested by trypsinization and plated on the upper chamber of each transwell at a density of $5 \times 10^{4}$ cells/ $100 \mu 1$ of serum-free McCoy's 5A modified media. Complete McCoy's 5A modified media was added to the lower chamber. The transwells were incubated at $37^{\circ} \mathrm{C}$ in a humidified incubator supplemented with $5 \% \mathrm{CO}_{2}$ for $48 \mathrm{~h}$, after which the cells in the upper chamber were removed and the upper-side of the membrane thoroughly cleaned. Cells that have invaded through the Matrigel-coated membrane were stained with crystal violet. Three independent experiments were carried out in triplicates for each treatment condition. 
Table I. RT-PCR primers.

\begin{tabular}{|c|c|c|c|c|}
\hline Gene & $\begin{array}{l}\text { Forward primer sequence } \\
\qquad\left(5^{\prime} \rightarrow 3^{\prime}\right)\end{array}$ & $\begin{array}{l}\text { Reverse primer sequence } \\
\qquad\left(5^{\prime} \rightarrow 3^{\prime}\right)\end{array}$ & $\begin{array}{c}\text { Primer annealing } \\
\text { temperature } \\
\text { used }\left({ }^{\circ} \mathrm{C}\right)\end{array}$ & $\begin{array}{l}\text { Size of PCR } \\
\text { product } \\
\text { (bp) }\end{array}$ \\
\hline ANXA10 & GGCCGGGACCTGATTGG & AGCAGTAGGCTTCTCGCAT & 56 & 208 \\
\hline BMP4 & CCTGCGGTCCTTCGCT & TGCTTAGGGCTACGCTTGG & 60 & 233 \\
\hline BTBD3 & ACGCAAGGTTCTAGGAAAGGC & GCACACGACTGGAAACGGT & 56 & 219 \\
\hline DSC2 & AAAACTTAGTGTGAGTTTGTTCATCAC & AAAATGATGAAAATGGACAAAGC & 56 & 250 \\
\hline FN (fibronectin) & AAGAGCGAGCCCCTGA & ACCTACATTCGGCGGGTAT & 52 & 303 \\
\hline HOXC10 & CCGAACATCTGGAATCGCCT & АССТCTTCTTCCTTCCGCT & 56 & 267 \\
\hline JAG1 & GGGCGAGTGTCGGTCT & GGCTCGCAAGCGATGT & 52 & 213 \\
\hline MMP9 & CCGACCCGAGCTGACT & AGCGGTACATAGGGTACATGAG & 54 & 286 \\
\hline MYO6 & CATCCGCCCTGCCGAC & GCACCACGCTTCCGAGT & 56 & 201 \\
\hline OCLN (occludin) & AAGGGAAGAGCAGGAAGGTC & СТCСАACCATCTTCTTGATGTG & 60 & 396 \\
\hline PALD & TGGTGCGTGAGAACGG & CCCAATACACGACATTCC & 52 & 225 \\
\hline PDLIM5 & TGCCCGAGAGCCTGGAC & GGGCGCACATCGGAGTTC & 58 & 288 \\
\hline RHOB & CCAGGAGGACTACGACCG & CCTTCCTTGGTCTTGGCAG & 58 & 312 \\
\hline S100A4 & ACTGCTGTCATGGCGT & CGTTACACATCATGGCGATGC & 50 & 270 \\
\hline SOX9 & CGAACGCACATCAAGACGG & GCGGGATGGAAGGGACC & 60 & 291 \\
\hline TMOD3 & TCAGTCTTGCAGCCACCC & GTTCGTGGTCCCTGCTGT & 58 & 292 \\
\hline ZNF161 & AGCCGAACTTCGTTGGTCT & AGTCATCCGGTCCTTCCTC & 58 & 285 \\
\hline GAPDH & АTCTCTGCCCCCTCTGCTGA & GATGACCTTGCCCACAGCCT & 60 & 302 \\
\hline
\end{tabular}

Establishment and characterization of metastatic variants from HCT116 cell line. Five-week-old female athymic mice were purchased from Animal Resources Centre (Canning Vale, Australia) and maintained under specific pathogen-free conditions. The in vivo selection procedure used for the generation of metastatic variants from HCT116 colon cancer cell line has been described (18). Briefly, $2 \times 10^{6}$ cells suspended in $0.05 \mathrm{ml}$ of PBS was injected into the medial spleen tip. Six to eight weeks after injection, the animals were sacrificed and post-mortem examination performed. The hepatic metastatic nodules were obtained, washed in McCoy's 5A modified medium containing $10 \% \mathrm{FBS}, 100 \mathrm{U} / \mathrm{ml}$ penicillin, $100 \mu \mathrm{g} / \mathrm{ml}$ streptomycin and $0.25 \mu \mathrm{g} / \mathrm{ml}$ amphotericin $\mathrm{B}$, and minced. Following incubation with $50 \mathrm{U} / \mathrm{ml}$ dispase I for 30-60 min at $37^{\circ} \mathrm{C}$, the dispersed cells were filtered through a $100 \mu \mathrm{m}$ filter. The cells obtained from the hepatic metastatic nodules after the first passage was named M1. The procedure of in vivo selection was repeated twice to obtain the M2 and M3 cell lines, respectively. Clonal line E1 was isolated from the M3 cell line using the limiting dilution technique. HCT116 and its derived cell lines were then characterized for their metastatic ability by injecting $1 \times 10^{6}$ cells into the spleen of nude mice and the number of liver metastases counted after 8 weeks, unless the mice were assessed to be in a moribund state, in which case they were sacrificed earlier.

Western blot analysis and co-immunoprecipitation. Equal amounts of proteins extracted using lysis buffer (6 M urea, 1\% 2-mercaptoethanol, $50 \mathrm{mM}$ Tris buffer $\mathrm{pH} 7.4,1 \%$ SDS in PBS pH 7.4) were resolved on a $10 \%$ gel, transferred to nitrocellulose membrane (Hybond C-Extra, Amersham Biosciences) and probed for the expression of E-cadherin, $\beta$-catenin, $\alpha$-catenin, p120-catenin, $\alpha$-actinin and palladin. For the detection of phosphorylated Erk and total Erk expression, cells were lysed in extraction buffer (20 mM Tris- $\mathrm{HCl}$ pH 7.5,
$150 \mathrm{mM} \mathrm{NaCl}, 1 \mathrm{mM}$ EDTA, 1 mM EGTA, 1\% Triton X-100, $2.5 \mathrm{mM}$ sodium pyrophosphate, $1 \mathrm{mM}$ ß-glycerophosphate, $1 \mathrm{mM}$ sodium orthovanadate) and used immediately. Expression of GAPDH was used as loading control in all experiments. Monoclonal antibodies $(\mathrm{mAb})$ were obtained from Chemicon International Inc. (E-cadherin), Santa Cruz Biotechnology Inc. (ß-catenin, $\alpha$-actinin, GAPDH) and BD Transduction Labs. ( $\alpha$-catenin, p120-catenin). Polyclonal antibodies against palladin were purchased from Proteintech Group Inc., while those against total p44/42 MAP kinase (Erk1 and Erk2) and phospho-44/42 MAP kinase (Erk1 and Erk2) from Cell Signaling Technology. The method for coimmunoprecipitation has been described (14). The polyclonal anti-palladin antibody from Proteintech was used for immunoprecipitating palladin and its interacting proteins.

Flow cytometry (FACS). Cells were detached by incubation with $0.5 \mathrm{mM}$ EDTA/PBS at $37^{\circ} \mathrm{C}$ for $5 \mathrm{~min}$. Cells were preincubated with $20 \%(\mathrm{v} / \mathrm{v})$ goat serum (Dako Cytomation) for $20 \mathrm{~min}$ on ice, and then with the respective primary antibodies or isotype control antibodies diluted in FACSwash [2.5\% (v/v) FBS in PBS] for $1 \mathrm{~h}$ on ice. Subsequently, the respective FITCconjugated secondary antibodies were added and incubated for a further $30 \mathrm{~min}$ to $1 \mathrm{~h}$. Flow cytometry was carried out using the FACScalibur (Becton-Dickinson Immunocytometry Systems). The data were analyzed using the WINMDI v2.8 software (Scripps Institute). The anti- $\alpha 6$ and anti- 34 integrin antibodies were from Chemicon International Inc.

Reverse transcription-PCR (RT-PCR). Cells were cultured to similar densities and RNA extracted using RNeasy Mini Kit (Qiagen). RT-PCR of specific genes were amplified with primers listed in Table I with cycle conditions of $94^{\circ} \mathrm{C}$ for $30 \mathrm{sec}$, primer annealing temperature Tm for $30 \mathrm{sec}, 72^{\circ} \mathrm{C}$ for $30 \mathrm{sec}$, for $25-35$ cycles. 
Immunofluorescent staining. Cells cultured on glass coverslips were fixed with $3.7 \%$ paraformaldehyde in PBS and permeabilized with $0.5 \%$ Triton $\mathrm{X}-100$. The cells were blocked in $20 \%$ goat serum (Dako Cytomation) and then incubated with the appropriate $\mathrm{mAb}$ against E-cadherin (Sigma-Aldrich), B-catenin (Santa Cruz), $\alpha$-actinin (Santa Cruz), p120-catenin (BD Transduction Labs.) or polyclonal antibody against $\alpha$-catenin (Sigma-Aldrich), palladin (Proteintech) or Alexa Fluor 488 Phalloidin (Molecular Probes, Invitrogen). Secondary antibodies used were either Alexa Fluor 488conjugated goat anti-mouse, or anti-rabbit IgG (Molecular Probes). Images were captured using the Olympus Fluoview FV1000 confocal microscope.

Microarray data collection and analysis. Microarray analysis was performed on the HCT116 cell line and its 7 metastatic derivatives using Affymetrix HGU133A chips (Affymetrix Inc.). RNA extracted from the cell lines were processed according to the protocol outlined in the Affymetrix technical manual. Three independent biological replicates were profiled for each of the cell lines. MicroArray Suite 5.0 (MAS) (Affymetrix Inc.) was used for the initial analysis of the scanned images. For absolute analysis, each chip $(n=3)$ was scaled to a target intensity of 500 and probe sets were assigned a signal intensity and detection call of 'Present, Marginal or Absent'. The absolute data (signal intensity, detection call and detection p-value) were exported into GeneSpring v7.2 software (Silicon Genetics) for further analysis by parametric test based on the crossgene error model (PCGEM). Firstly, all of the measurements on each chip were divided by the 50th percentile value (per chip normalization). Secondly, each gene was normalized to the baseline value of the control samples (per gene normalization) using the mean. Genes from 'all genes' with expression control signal greater than 20 in at least $45 \%$ of the conditions were selected. Genes 'Present' or 'Marginal' in at least $18 \%$ of the samples were then selected. Subsequently, the genes were filtered on a fold change of 2 or greater against controls (values obtained for HCT116 cell line) in at least one of the 7 metastatic cell lines studied. ANOVA was used to identify differentially expressed genes $(\mathrm{p}<0.05)$ and the Bonferroni multiple testing correction was applied to determine statistical significance. Finally, data representing replicates of the same experimental condition were averaged. For this study, further selection from the above list was carried out for genes demonstrating at least a 2-fold change in E1 compared to HCT116. A total of 93 unique genes (114 probe sets), of which 43 are up-regulated and 50 are down-regulated, met these criteria. The differentially expressed genes were annotated according to the Gene Ontology-Biological process (http://www.geneontology.org) and further clustered using the GeneSpring v7.2 software.

Wound healing assay. Cells were seeded in 6-well plates and grown for $24 \mathrm{~h}$ to confluency. A pipette tip was drawn carefully through the monolayer to create a wound between cells. To study the morphology and the migration pattern of the cells at the wound front, still images (x20 magnification) were captured at $24 \mathrm{~h}$ post-wounding. For live-imaging of cell movements during the wound healing process, the cells were treated as above, then transferred to a heated stage attached to the Olympus Fluoview FV1000 microscope. The conditions were maintained at $37^{\circ} \mathrm{C}, 5 \% \mathrm{CO}_{2}$ and with a water reservoir to maintain humidity. The field of view was centered over a section of the wound front and phase images captured for the next $18 \mathrm{~h}$ (at 1 frame $/ 5 \mathrm{~min}$ ) using time-lapse microscopy. Images were saved as 'compressed AVI Files', using the Olympus Fluoview 1.3 software, to generate the video.

Immunohistochemistry. Eighteen matched tissue samples of normal colonic mucosa, tumor and liver metastases were obtained from the National University of Singapore (NUS), Department of Pathology. Informed patient consent was obtained for all of the cases. The use of the tissue samples for this project was approved by the NUS Institutional Review Board. Immunohistochemical analysis was performed using a standard indirect immunoperoxidase method. Thick sections ( $4 \mu \mathrm{m})$ of formalin-fixed, paraffin-embedded tissues were deparaffinized, underwent antigen retrieval at $95^{\circ} \mathrm{C}$ for $10 \mathrm{~min}$ using Tris-buffered solution at pH 9.0 (Dako) followed by treatment with hydrogen peroxide for $5 \mathrm{~min}$. Rabbit polyclonal antibody against palladin (Proteintech) was used at a dilution of 1:1000, with overnight incubation at room temperature. This was followed by the usage of a non-avidin-biotin polymerbased detection method (Envision+, Dako). Hematoxylin was used as counterstain. The 18 matched samples were treated under similar conditions of fixation, embedding and storage. Palladin expression in muscle cells was considered the appropriate internal control to assess the adequacy of the procedure. Images were taken using a Nikon ECLIPSE 90i microscope.

\section{Results}

The E1 cell line, a metastatic variant derived from poorly metastatic HCT116 human colon cancer cell line, has an EMT-like phenotype and is more invasive. Metastatic cell lines were derived from the poorly metastatic human colon cancer cell line HCT116 by serial transplantation in athymic nude mice, according to a well-established model for metastatic colorectal cancer (18). Briefly, the HCT116 cells were injected into the sub-capsular region of the spleen and the resulting metastatic nodules in the liver were harvested and expanded into derivative cell lines. Clonal lines including E1 were derived from the liver metastatic tumor nodules by means of limiting dilution. Histopathology of the tumors in the liver and spleen of the nude mice showed adenocarcinoma confirming that the tumors were derived from the cells injected (data not shown). Karyotype analysis using mFISH and qFISH techniques showed that all the derivative cell lines displayed similar non-reciprocal translocations $(\mathrm{t} 8,16 ; \mathrm{t} 16,10 ; \mathrm{t} 17,18)$ as those found in the parental HCT116 cell line (data not shown).

Monolayer cultures of the derived cell lines showed similar epithelial morphology compared to the HCT116 cell line in phase-contrast microscopy, except that of the E1 cell line. The E1 cell line exhibited a mesenchymal/fibroblastoid spindle-shaped morphology, loss of contact inhibition of growth and reduced intercellular contacts even at high density, when compared to the parental HCT116 cells (Fig. 1A). When cultured as suspension cultures in low cluster plates, HCT116 
A

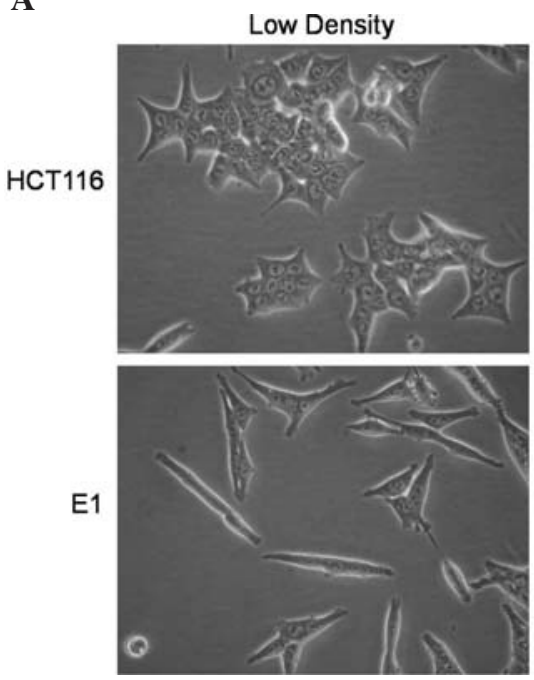

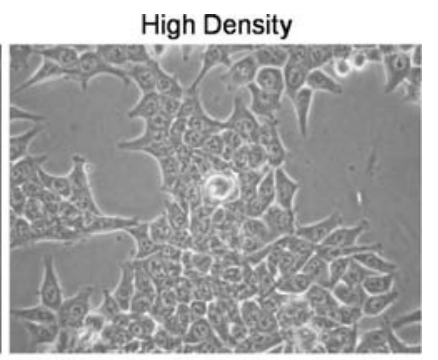

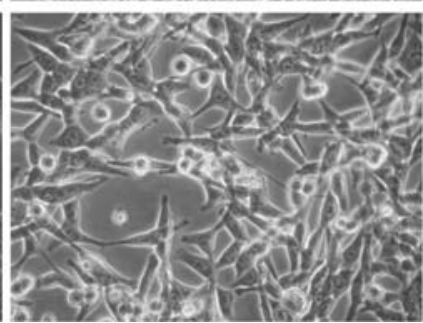

B
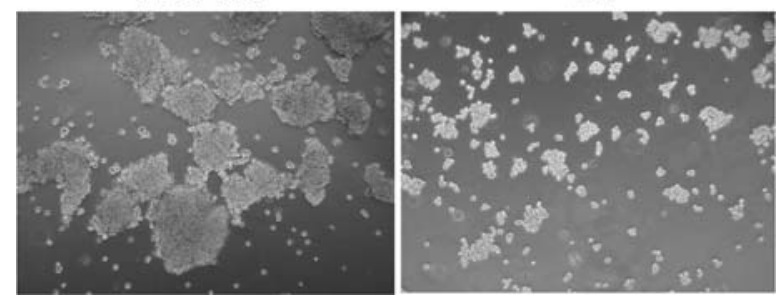

C

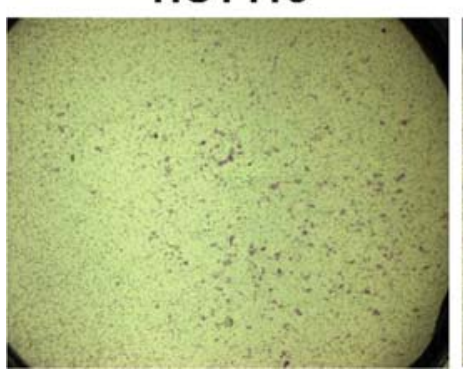

HCT116
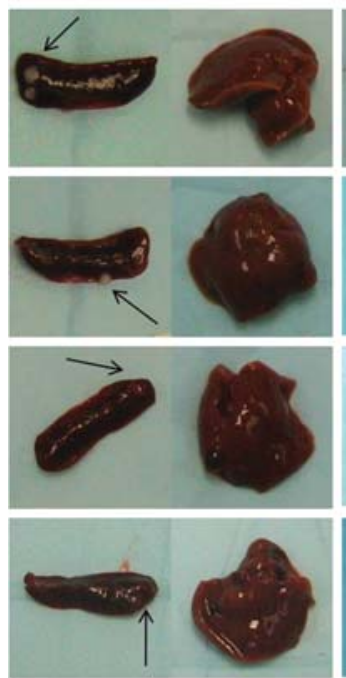

Spleen
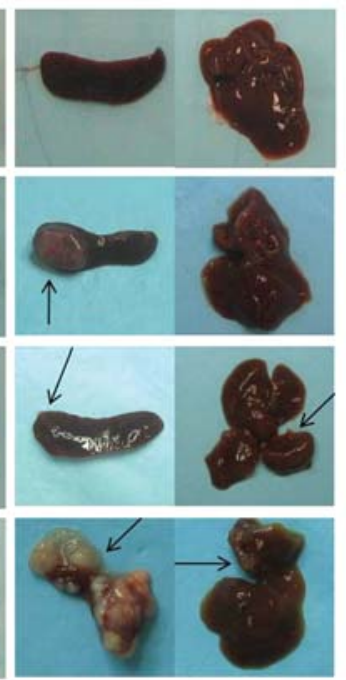

Spleen
Liver

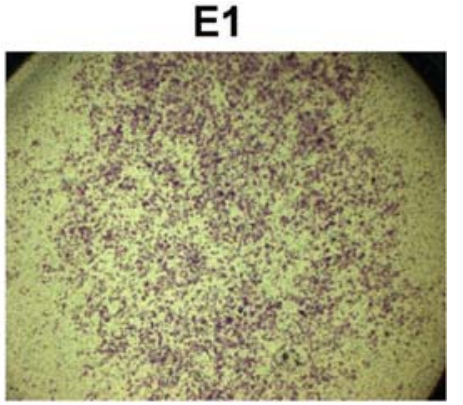

E1
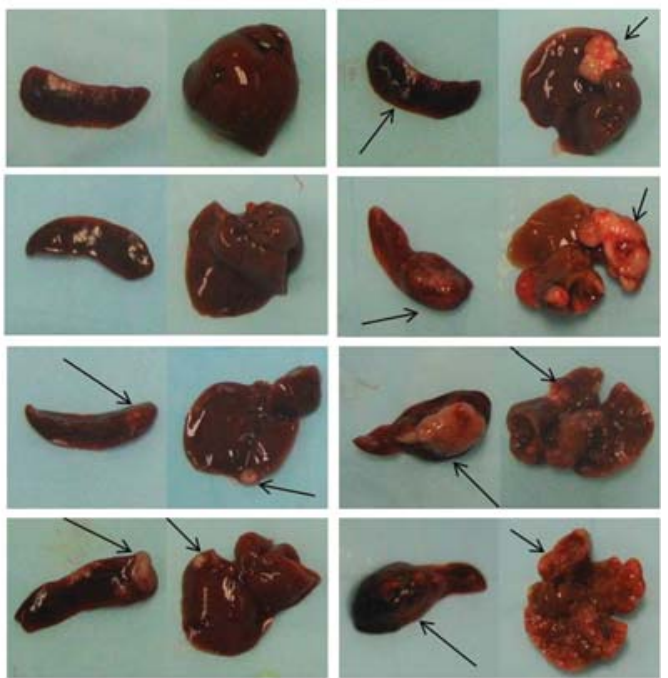

Spleen

Liver

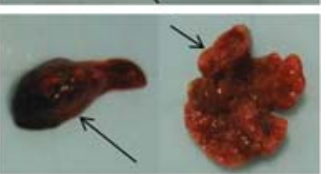

Spleen Liver

$\mathbf{D}(\mathbf{b})$

\begin{tabular}{|c|c|c|c|c|}
\hline \multirow{2}{*}{$\begin{array}{c}\text { Cell Line } \\
\text { Injected }\end{array}$} & \multicolumn{4}{|c|}{ Number of mice that developed $(x)$ number of liver } \\
\cline { 2 - 5 } & $\mathrm{x}=0$ & $1 \leq \mathrm{x}<5$ & $5 \leq \mathrm{x}<30$ & $\mathrm{x} \geq 30$ \\
\hline HCT (8) & 6 & 2 & 0 & 0 \\
\hline E1 (8) & 2 & 3 & 1 & 2 \\
\hline
\end{tabular}

Figure 1. The morphology, invasiveness and metastatic potential of HCT116 and E1 cells. A, Phase-contrast microscopy showing the morphology of HCT116 and E1 cells cultured at low (left panel) and high densities (right panel). B, Suspension cultures of HCT116 and E1 cells in low cluster plates. C, In vitro invasion assays were carried out for the HCT116 and E1 cell lines. Crystal violet staining of cells that have invaded through the Matrigel-coated $8 \mu \mathrm{m}$ poresize membranes of Transwell ${ }^{\circledR}$ chambers is shown. The images are representative of 3 independent experiments carried out in triplicates for each respective cell line. D, Mice were injected intrasplenically with $1 \times 10^{6}$ cells and sacrificed after 6-8 weeks, at which time the number of liver metastases nodules was determined. Shown are pictures of the spleen and liver obtained from mice injected with the respective HCT116 and E1 cell lines. Arrows indicate splenic tumor and liver metastatic nodules. The number of mice, injected with the respective HCT116 and E1 cells, that developed liver metastases was tabulated. 
cells formed compact, dense multi-cellular spheroids with tight intercellular adhesions, whereas E1 cells aggregated loosely in suspension (Fig. 1B). The invasive ability of HCT116 and E1 cells was studied using the Matrigel-coated transwell system. E1 cells showed an increased ability to invade through the pores of the Matrigel-coated membrane compared to HCT116 cells (Fig. 1C). The E1 cell line was also more metastatic than the HCT116 cell line when injected intrasplenically in nude mice. Metastatic tumors to the liver developed in $75 \%$ of nude mice (6 of 8 mice) injected with E1, compared to $25 \%$ of nude mice ( 2 of 8 ) injected with HCT116 (Fig. 1D). Of the mice with metastatic liver tumors, those injected with E1 developed significantly more nodules than those injected with HCT116, with at least 5 and up to more than 30 nodules observed in 3 of 6 mice. In contrast, intrasplenic injections of HCT116 did not generate more than 4 metastatic nodules in either of the 2 mice with metastatic disease (Fig. 1D). The reduction in intercellular adhesion and an acquisition of a mesenchymal/fibroblast-like morphology, together with a more invasive and metastatic phenotype suggest that the E1 cells could have undergone epithelial-mesenchymal transformation (EMT), which has been implicated as an important process in metastasis $(6,8)$.

The loss of intercellular adhesion in E1 cells is associated with a cytoplasmic localization of E-cadherin. Besides a change in gross morphology and the loss of intercellular adhesion, EMT is also characterized by changes in the expression of various epithelial and mesenchymal proteins, as well as cytoskeleton reorganization. Actin organization in the HCT116 and E1 cell lines was studied by staining the actin cytoskeleton with phalloidin and visualization with confocal microscopy. HCT116 cells exhibited numerous spike-like filopodia and stress fibres at the cortical surface. In contrast, the E1 cell line, showed reduced filopodia and cortical stress fibres, with more prominent lamellipodia (Fig. 2A). As filopodia formation is a feature of epithelial cell movement, which occurs in events such as epithelial sheet closure during development (19), reduced filopodia formation in E1 cells suggests that these cells have acquired a mesenchymal/ fibroblast-like phenotype.

We also investigated the mesenchymal transformation in the E1 cells by determining the expression of a number of well-characterized epithelial and mesenchymal markers. Although the loss of E-cadherin (epithelial marker) expression leading to the disruption of E-cadherin-dependent junctions is one of the hallmarks of EMT $(6,20)$, we did not detect a loss of E-cadherin expression in the E1 cells (Fig. 2B). However, dissolution of the adherens junction was associated with a cytoplasmic localization of E-cadherin in E1 cells, indicative of a mesenchymal phenotype (21), compared to its localization at the intercellular junction in HCT116 cells (Fig. 2A). Cytoplasmic localization, without a loss in protein expression (Fig. 2B), was also observed for other proteins in the E-cadherin-catenin complex (i.e. $\beta$-catenin, $\alpha$-catenin, $\alpha$-actinin, p120-catenin) in E1 cells, indicating that the E-cadherin-catenin complex may be disrupted without necessarily losing the expression of any of its components. These proteins exhibited adherens junction localization in HCT116 cells (Fig. 2A).
The E1 cells showed a down-regulation in expression of other epithelial or polarity markers, such as integrin $\alpha 6 \beta 4$ (Fig. 2C), the tight junction protein occludin (Fig. 2D) and the desmosome protein desmocollin DSC2 (Fig. 2D) $(12,22,23)$. Other mesenchymal markers such as fibroblast-specific protein-1 (FSP-1/S100A4), fibronectin (Fn) and matrix metallopeptidase 9 (MMP9) were up-regulated in E1 compared to HCT116 cells (Fig. 2D). However, vimentin, another mesenchymal marker, was not detected in E1 cells using either Western blot analysis or RT-PCR (data not shown). The loss/gain in expression of some epithelial/mesenchymal markers, without a change in expression of E-cadherin and vimentin, indicate that there are additional mechanisms involved in the disruption of E-cadherin-dependent junctions and mesenchymal transformation in E1 cells apart from suppression of E-cadherin and vimentin expression. In fact, there are many examples where advanced metastatic carcinoma cells adopt only a subset of mesenchymal features and retain the characteristics of well-differentiated epithelial cells or exhibit an absence of the end-point defining characteristics of EMT. For example, carcinoma cells may exhibit a metastatic and mesenchymal-like phenotype but do not show a reduction in E-cadherin expression (24-28). This has led to the concept of 'incomplete EMT' (29) and metastatic cells possessing both epithelial and mesenchymal features (28). Hence, it appears that EMT does not constitute a single 'on-off', end-point defined process, but rather, is a continuum of change towards a mesenchymal phenotype (22).

Therefore, this loss/gain in expression of some epithelial/ mesenchymal molecular markers, cytoskeleton reorganization, together with the data on the loss of intercellular adhesion, an elongated cell shape and increased invasiveness and metastatic potential, is consistent with a mesenchymal change in the E1 cells.

Genes involved in intestinal epithelium development and cytoskeleton organization are amongst those that are differentially regulated in the El cells. To identify novel genes associated with metastasis and invasiveness, transcriptomic microarray analysis was carried out on the HCT116 cell line and the E1 metastatic cell line derived from it. The gene list obtained from the comparison of E1 versus HCT116 was filtered to exclude very low expression signals. Genes demonstrating at least 2-fold change in E1 compared to HCT116 were subjected to statistical analysis to determine significance at $\mathrm{p}<0.05$ (two-way ANOVA followed by Bonferroni multiple testing correction). A total of 93 unique genes (114 probe sets), of which 43 are up-regulated and 50 are down-regulated, met these criteria. Fig. 3A shows a list of the genes classified based on Gene Ontology Biological Processes (GO BP). Of these, S100A4 has been shown to be an important metastasis mediator (30). PLEC1 is a potential metastasis suppressor gene $(31,32)$, whilst the up-regulation of Jag1, Sox4, HMGA1, SEMA3A, CD24 has been associated with metastasis and/or invasiveness, with CD24 being a prognostic marker in the metastatic progression of colon cancer (33). Up-regulation of SATB1, which reprogrammes chromatin organization, has been presented as a new mechanism of tumor progression and metastasis in a recent publication (34). Four of the up-regulated genes, BMP4, 


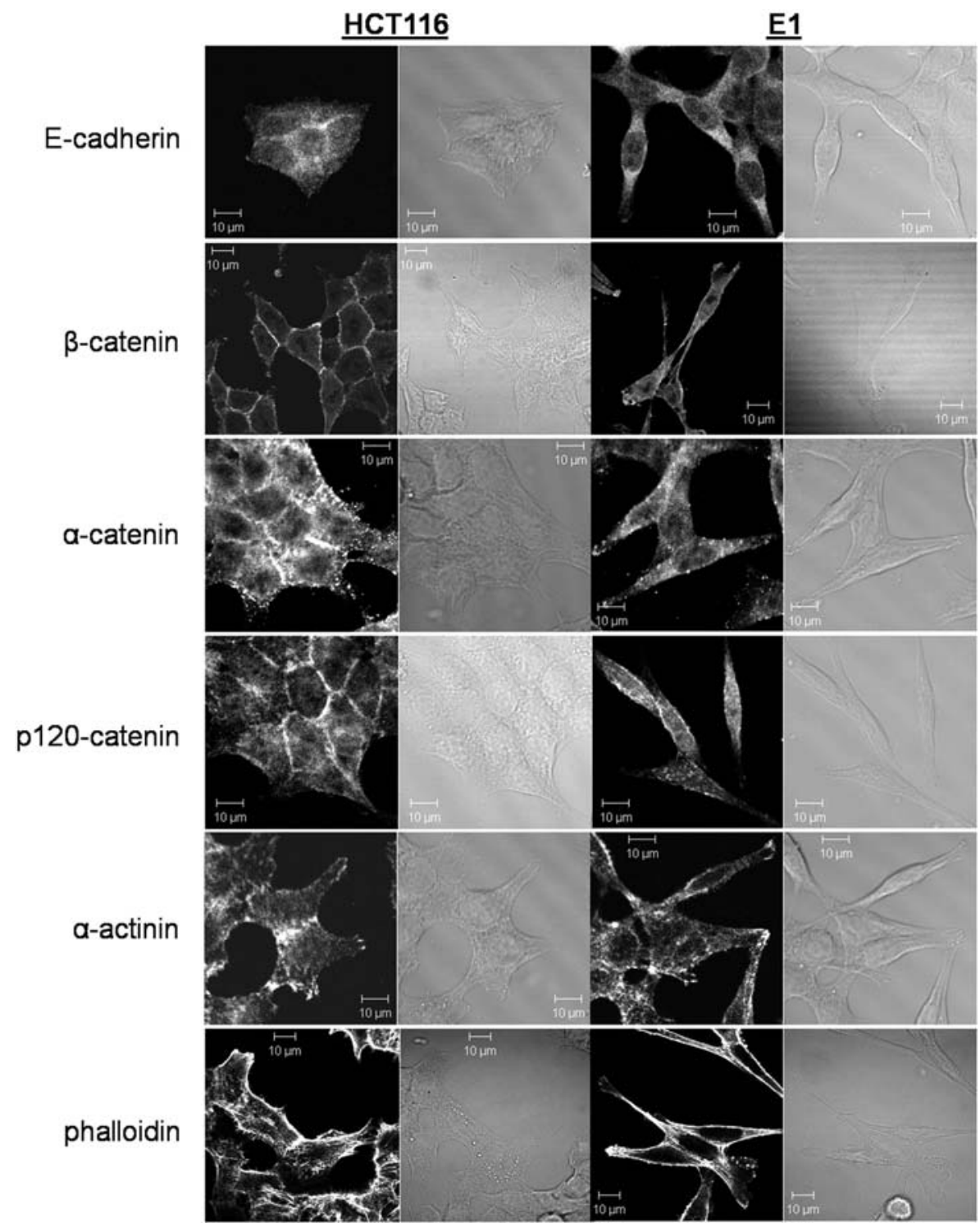

B

HCT E1

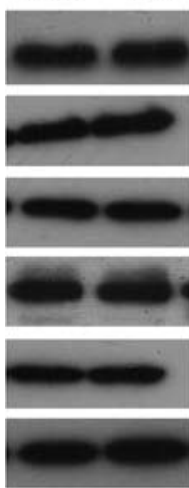

C

HCT116

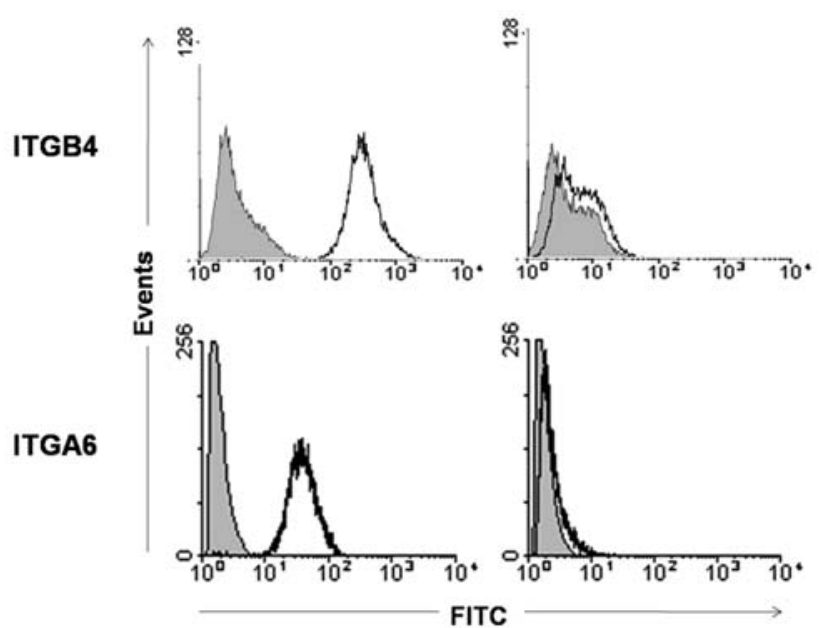

D

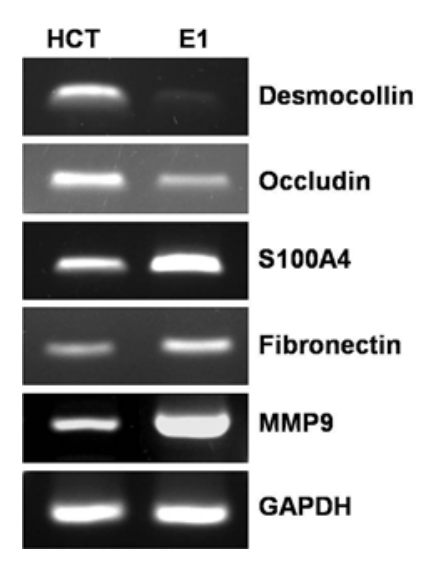

Figure 2. Expression and localization of epithelial and mesenchymal markers in HCT116 and E1 cells. A, Confocal microscopy images of HCT116 and E1 cells fluorescently stained with respective antibodies against E-cadherin, $\beta$-catenin, $\alpha$-catenin, p120-catenin, $\alpha$-actinin and phalloidin. B, Western blot analysis on the expression of E-cadherin, $\beta$-catenin, $\alpha$-catenin, p120-catenin and $\alpha$-actinin in HCT116 and E1 cells cultured to similar density ( 80\% confluent). GAPDH was used as a loading control. C, FACS analysis detecting for surface expression of integrins $\alpha 6$ and B4 in HCT116 and E1 cells. Open profiles are signals detected using the integrin antibodies, shaded profiles are signals detected using isotype control antibody. D, mRNA expression of epithelial/polarity markers (desmosome, occludin) and mesenchymal markers (S100A4, fibronectin, MMP9) was studied by RT-PCR using RNA extracted from HCT116 and E1 cells cultured to a similar density ( $\sim 80 \%$ confluent). GAPDH was used as a loading control. 
A

HCT / E1

1

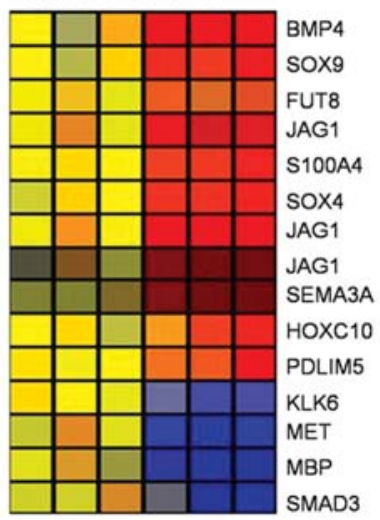

2
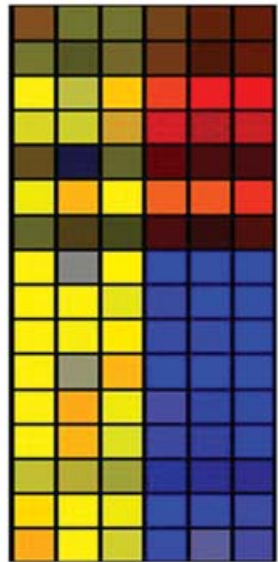

3

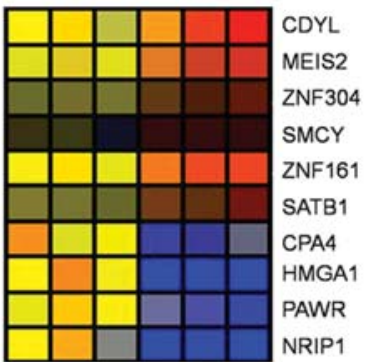

HCT / E1

4

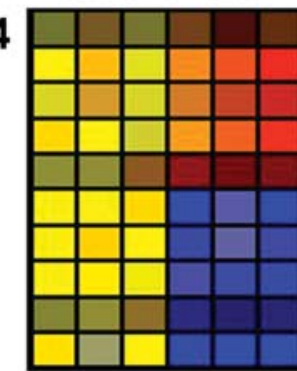

5
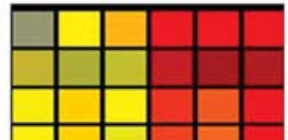

ARL7

INPP4B

PDE4B

TNIK

PEG10

RHOB

PEG10

RHOGDI

F2RL1

HAN11

RHOGDI

IQGAP1

PRKCL2

ADRBK1

CAV1

SHARP

6

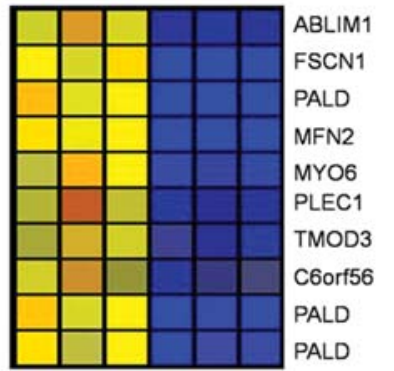

HCT / E1

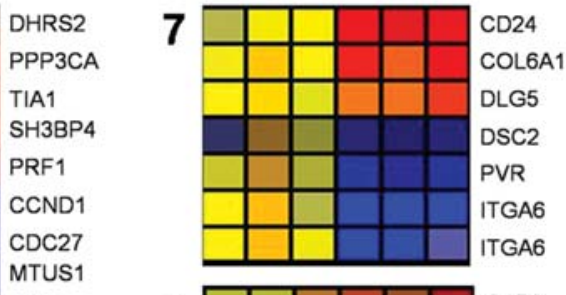

8

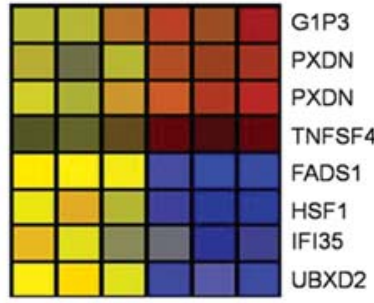

9
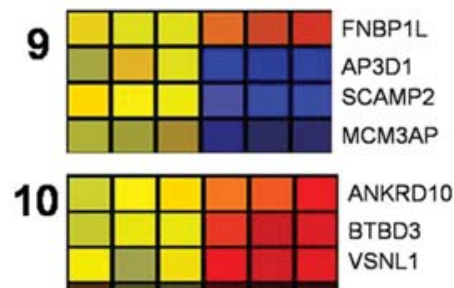

ANKRD10

BTBD3

VSNL1

VSNL1

PRKCDBP

ORAOV2

ANXA10

SLC38A1

UBE2H

PTBP1

UBE2H

Figure 3. Classification and validation of genes that were dysregulated in E1 compared to HCT116 cells. A, Heatmap showing genes that were dysregulated (at least 2-fold) in E1 compared to HCT116 cells. Triplicate chips were used for each cell line. Blue shades represent a down-regulation and red shades an up-regulation in gene expression of E1 relative to the HCT116 cell line. Genes were classified based on Gene Ontology Biological Processes (GO BP) into 10 groups: 1, development/cell differentiation/epithelial-mesenchymal transition (EMT)/cell fate commitment; 2, signal transduction; 3, regulation of transcription/chromatin structure; 4 , cell cycle/cell proliferation/cell death and apoptosis; 5 , biosynthetic process/metabolism; 6 , organelle/membrane/ cytoskeleton organization and biogenesis; 7, cell adhesion/cell motility; 8, immune response/response to stress; 9, transport/endocytosis; 10, others. B, mRNA expression levels of the different genes in E1 relative to HCT116 based on RT-PCR results and microarray data are shown. The microarray data is represented by the heatmap of gene expression profiles of HCT116 and E1 cell lines.

Jag1, S100A4 and Sox9, are also known to induce EMT during cancer progression and/or development (35-39).

Interestingly, several of the dysregulated genes are involved in signaling pathways that are important for intestinal epithelium development and intestinal stem cell maintenance: i) BMP4, CCND1, Met, Jag1, Sox9, Sox4 are known target 
genes of the Wnt/B-catenin signaling pathway (obtained from Roel Nusse's recent work on colorectal cancer, http://www. stanford.edu/ rnusse/wntwindow.html), ii) BMP4, FUT8, Smad3 and PEG10 belong to the TGFß/BMP signaling pathway, iii) Jag1 is a ligand for the Notch pathway. The dysregulation of genes in pathways involved in intestinal development further validates the relevance of the gene list for colon cancer metastasis. Another potentially interesting

A HCT E1 \#1 \#2 \#3 \#4 GCctl

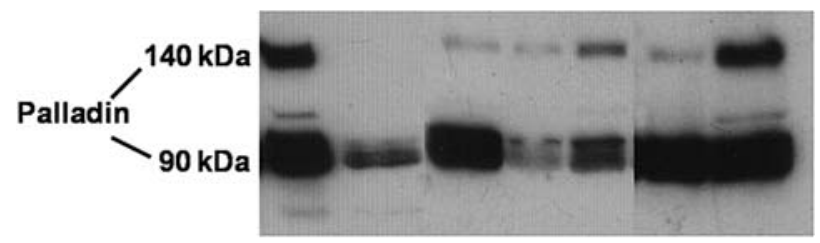

GAPDH

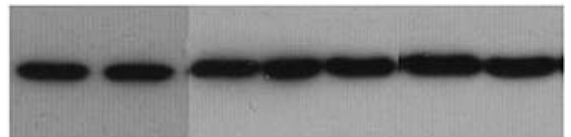

and important set of genes identified are those involved in cytoskeleton organization/actin binding and cell adhesion. Many of these, e.g., PDLIM5, ABLIM1, palladin, DLG5, have domains such as PDZ, LIM, Ig, ZnF, proline-rich, actin binding domains that allow for protein-protein interactions and could act as scaffolds for formation of multiprotein complexes $(13,40-43)$. These proteins could mediate interactions between actin filaments/cytoskeleton and cytoplasmic targets, functioning in the transmission of extracellular signals to the cytoskeleton. The functions of this set of genes may explain the morphological changes observed in the transition of epithelial HCT116 to the more mesenchymal, metastatic E1 cells. For example, the loss of PLEC1 and ITGA6, both components of hemidesmosomes $(44,45)$, might result in the disruption of hemidesmosomes and hence the detachment of a tumor cell from the basement membrane prior to its migration away from the tumor mass. DSC2, found primarily in epithelial cells and required for cell adhesion, desmosome formation (23), was down-regulated in the mesenchymal E1 cells. The actin filament pointed-end capping

B
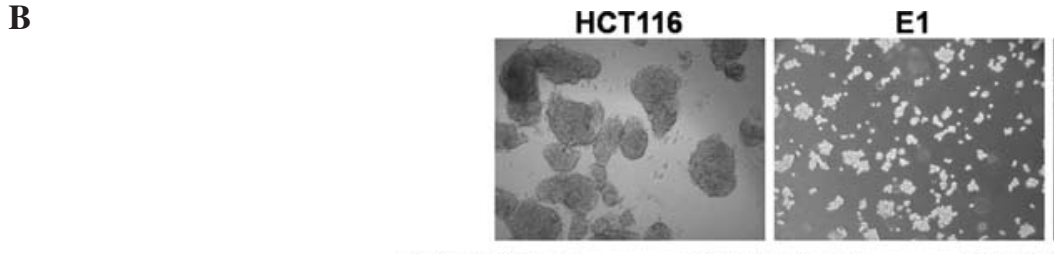

HCT GCctl
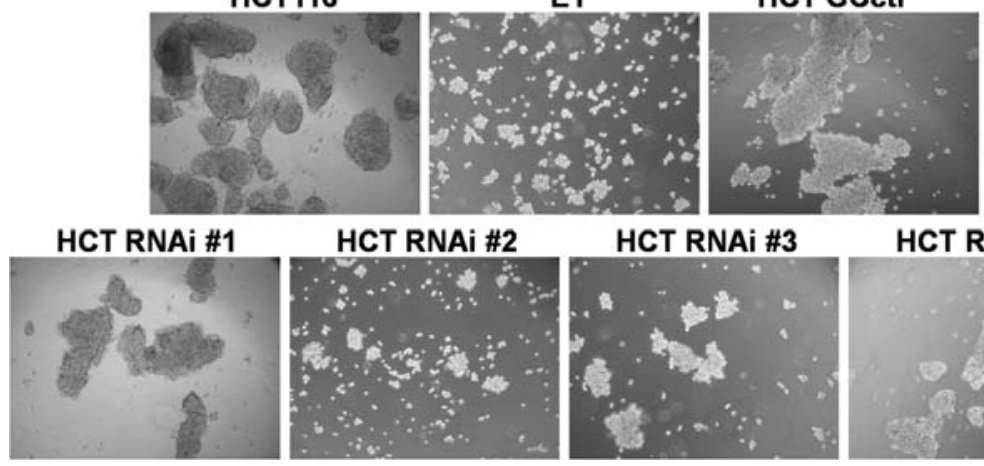

HCT RNAi \#4

C
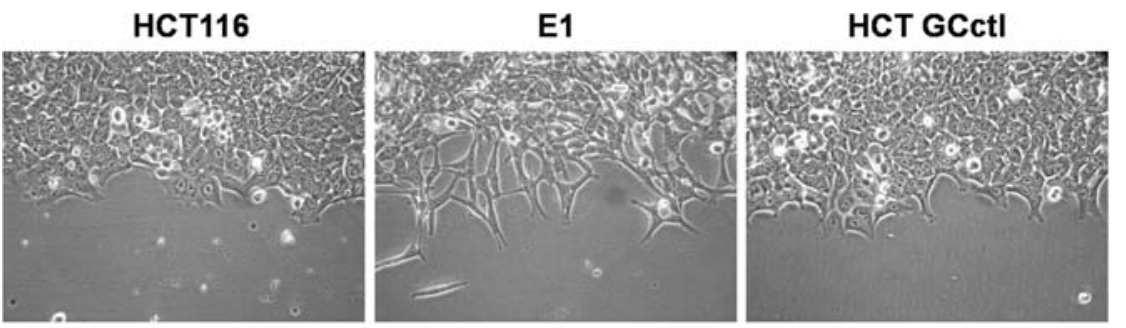

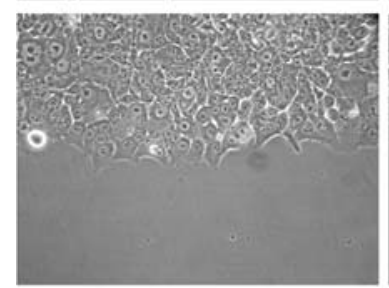

HCT RNAi \#1

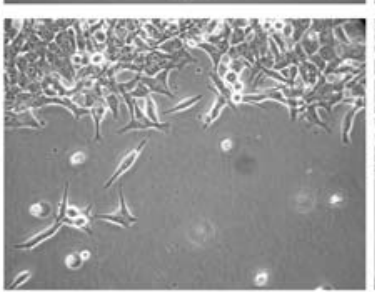

HCT RNAi \#2

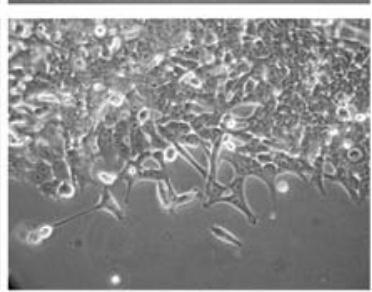

HCT RNAi \#3

Figure 4. Effects of palladin knockdown on intercellular adhesion, collective migration and localization. A, Western blot analysis of palladin expression in HCT116 and E1 cells, HCT116 cells transfected with control RNAi (GCctl), RNAi \#1, \#2, \#3 or \#4. RNAi \#1 and \#4 were designed to knockdown only the $140 \mathrm{kDa}$ palladin isoform, RNAi \#2 and \#3 were designed to knockdown both the 90 and $140 \mathrm{kDa}$ palladin isoforms. GAPDH was used as a loading control. HCT116 and E1 cells were cultured to a similar density $(\sim 80 \%)$ before protein extraction. Transfected cells were harvested for protein extraction at 48 h posttransfection. Similar profiles were obtained with cells harvested at 24, 72 and 96 h post-transfection (data not shown). B, Suspension cultures of HCT116 and E1 cells, HCT116 cells transfected with control RNAi (GCctl), RNAi \#1, \#2, \#3 or \#4. RNAi-transfected HCT116 cells were re-seeded into the low cluster plates at $24 \mathrm{~h}$ post-transfection. Cells were cultured in suspension for $24 \mathrm{~h}$ in the tissue culture incubator, after which images were taken with a camera attached to the Zeiss Axiovert microscope equipped with a x10 phase-contrast objective. C, Still images of the wound fronts of untransfected HCT116, E1 cells and HCT116 cells transfected with control RNAi (GCctl), RNAi \#1, \#2 or \#3. Transfected cells were re-seeded for the wound healing assay at 24 h posttransfection. Cells were seeded at the appropriate density such that they were $100 \%$ confluent after $24 \mathrm{~h}$ culture, upon which the monolayer was artificially wounded by scratching with a pipette tip. These images were captured at $24 \mathrm{~h}$ post-wounding. 
A
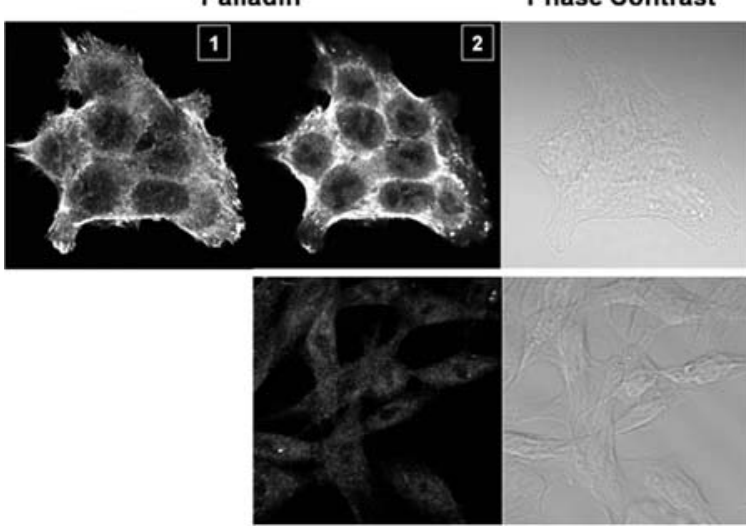

C

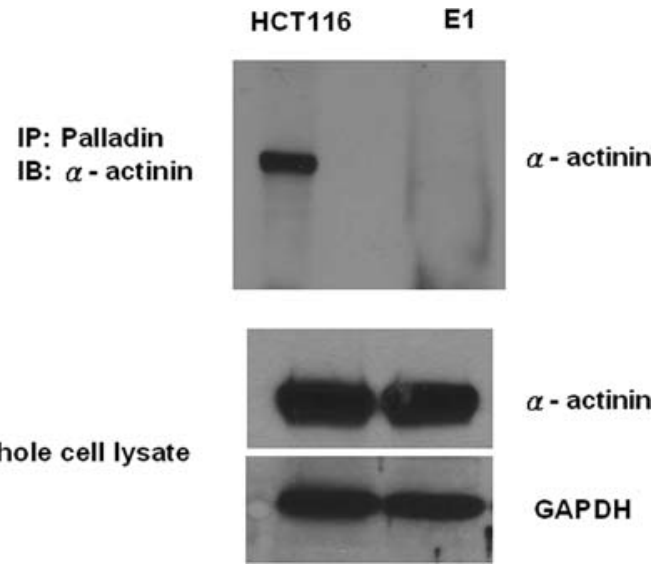

B

HCT116

E1

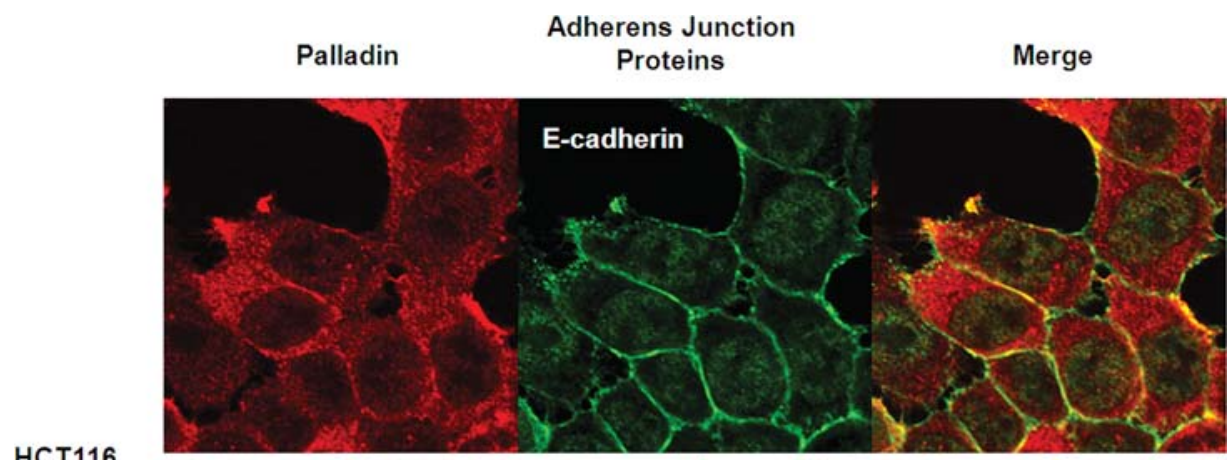

HCT116

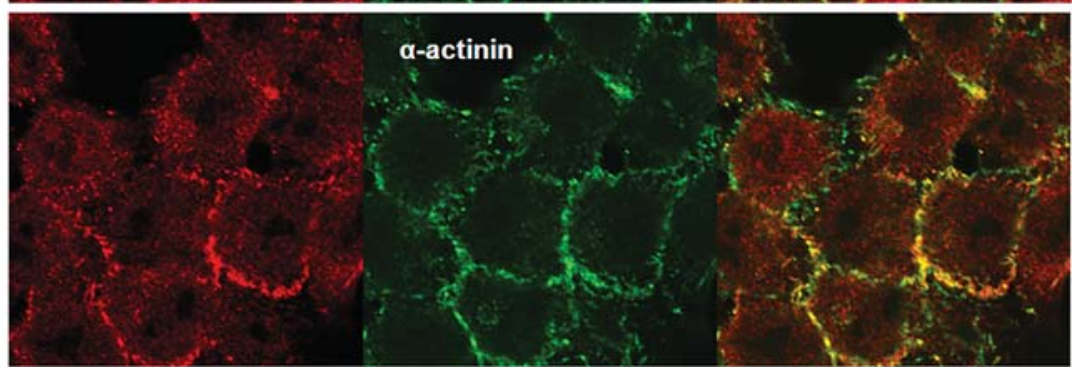

D

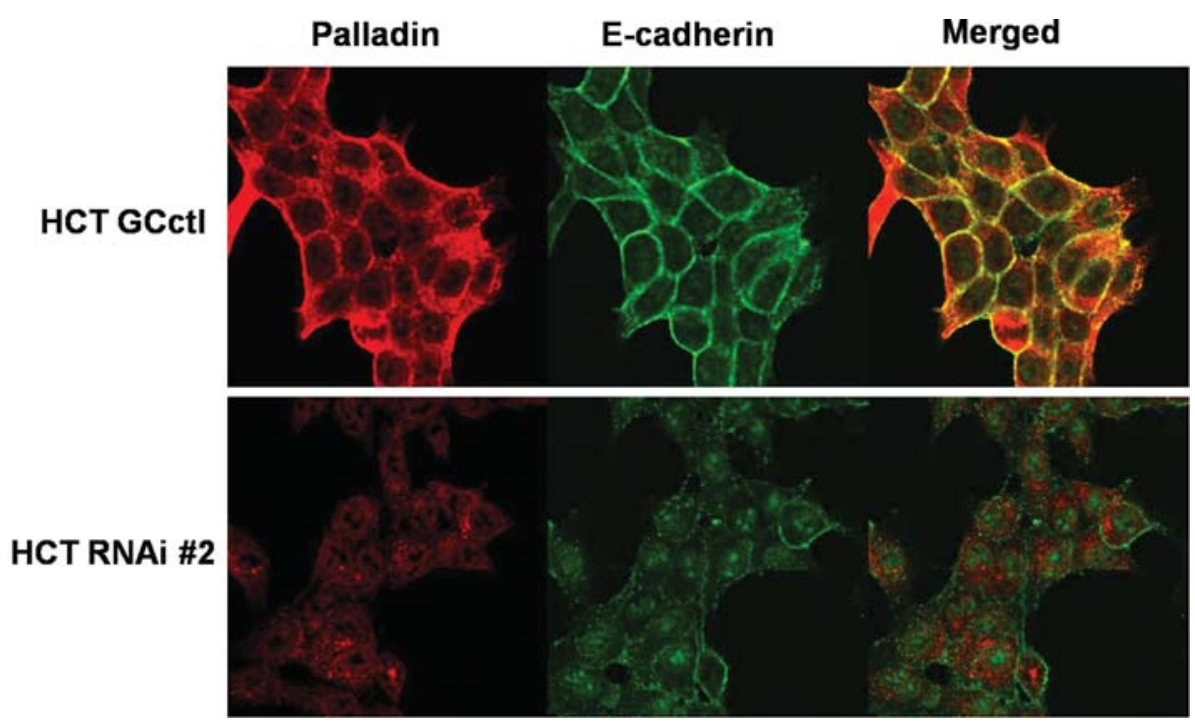

Figure 5. Effects of palladin knockdown on the expression and localization of palladin. A, Confocal microscopy images of HCT116 and E1 cells fluorescently stained with anti-palladin antibody. Two focal planes were captured for HCT116 cells: 1, plane 1 shows palladin staining at the focal adhesions, spike-like filopodia structures and 2, plane 2 shows the staining at adherens junction. B, Confocal microscopy images of HCT116 cells constained with anti-palladin antibody and either anti-E-cadherin antibody (upper panel) or anti- $\alpha$-actinin antibody (lower panel). C, Immunoprecipitates from the cell lysate using antipalladin antibody were probed with anti- $\alpha$-actinin antibody, which indicated that $\alpha$-actinin co-precipitated with palladin in HCT116 cells (upper panel). Samples of whole cell lysate were run as input control (lower panel). E1 sample that contained minimal palladin was run as a negative control. D, Confocal microscopy images of HCT116 cells transfected with control RNAi (GCctl) or RNAi \#2, co-stained with anti-palladin and anti-E-cadherin antibodies. Staining was carried out on transfected cells at $24 \mathrm{~h}$ post-transfection. 
$\mathbf{E}$

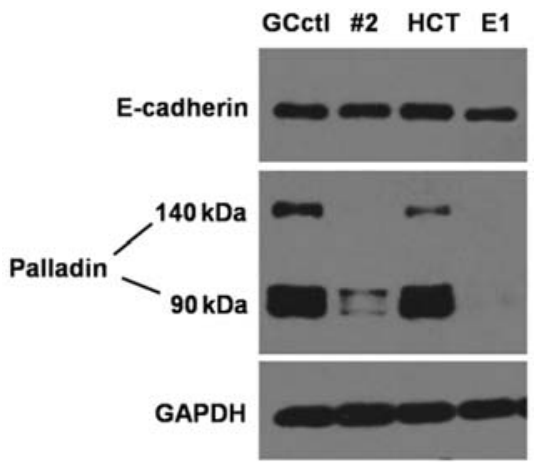

Figure 5. Continued. E, Protein extracts of HCT116, E1 cells and HCT116 cells transfected with control RNAi (GCctl) or RNAi \#2 (at 24 h posttransfection) were probed for palladin and E-cadherin. There was an almost complete knockdown in palladin expression in HCT RNAi \#2 cells, without any changes in E-cadherin expression.

protein TMOD3, which contributes to the regulation of polarized epithelial cell shape by stabilizing F-actin on lateral membranes, was also down-regulated in the E1 cells, consistent with the loss of polarity markers and epithelial morphology in these cells (46).

The changes in mRNA expression of S100A4, DSC2 (Fig. 2D), ANXA10, BTBD3, BMP4, HOXC10, Jag1, MYO6, Palladin, PDLIM5, RhoB, Sox9, TMOD3, ZnF161 observed in the microarray data were independently validated by RT-PCR (Fig. 3B).

Knockdown of palladin results in a reduction in intercellular adhesion and collective migration. Amongst the genes that were differentially regulated in E1 in comparison to HCT116 cells is palladin, an actin cross-linking protein that also acts as a scaffold for multiple actin-binding proteins, such as $\alpha$-actinin, VASP, profilin, ezrin and Eps8 (13). In the present study, we focused on examining whether the down-regulation of palladin contributed to the morphological changes as well as the loss of the intercellular adhesion observed in E1 cells. Palladin mRNA expression was confirmed to be down-regulated in E1 cells compared to HCT116 cells (Fig. 3B). Two isoforms of palladin were detected in HCT116 cells, a more abundant 90 and a $140 \mathrm{kDa}$ isoform (Fig. 4A), consistent with reports of palladin expression in other epithelial cell lines such as HeLa (14). The $140 \mathrm{kDa}$ palladin isoform is an $\mathrm{N}$-terminal extension of the $90 \mathrm{kDa}$ isoform, with an additional $\mathrm{IgC} 2$ domain and proline-rich region besides the $3 \mathrm{IgC} 2$ domains and a proline-rich region in the $90 \mathrm{kDa}$ isoform (15). There was a down-regulation of both isoforms in E1 cells, with an undetectable $140 \mathrm{kDa}$ isoform and a minimal expression of the $90 \mathrm{kDa}$ isoform (Fig. 4A). To analyze the functional roles of palladin, palladin expression was silenced using Stealth RNAi (Invitrogen) designed to knockdown either the $140 \mathrm{kDa}$ isoform (RNAi \#1,\#4) or both the 90 and $140 \mathrm{kDa}$ isoforms (RNAi \#2, \#3). It was not possible to knockdown only the $90 \mathrm{kDa}$ isoform, as the mRNA of the $140 \mathrm{kDa}$ isoform is a 5 ' extension of the $90 \mathrm{kDa}$ isoform. Transient transfection of HCT116 cells with RNAi \#1 or \#4 led to a significant decrease in expression of the $140 \mathrm{kDa}$ palladin isoform but not the $90 \mathrm{kDa}$ isoform, as detected by Western blot analysis (Fig. 4A). The expression of both the 90 and $140 \mathrm{kDa}$ isoforms was significantly reduced when RNAi \#2 or \#3 was used, with the former being able to achieve an almost complete knockdown of palladin expression (Fig. 4A). HCT116 cells transfected with control RNAi (HCT GCCtl) did not exhibit any significant changes in palladin expression (Fig. 4A) when compared to untransfected HCT116 cells. The knockdown of palladin expression lasted for $96 \mathrm{~h}$ (data not shown), which was sufficient for us to perform the various functional assays.

The effect of palladin down-regulation on intercellular adhesion was analyzed using a cell aggregation assay. Knockdown of both palladin isoforms resulted in a reduction of intercellular adhesion. HCT116 cells transfected with either RNAi \#2 or \#3 (HCT RNAi \#2, HCT RNAi \#3) targeted against both isoforms aggregated loosely as a suspension of small clusters, unlike their control RNAi-transfected counterparts (HCT GCctl) which still formed large aggregates or spheroids (Fig. 4B), resembling that of E1 cells. HCT116 cells transfected with RNAi \#1 or \#4 (HCT RNAi \#1, HCT RNAi \#4) targeted only against the $140 \mathrm{kDa}$ isoform formed large spheroids, resembling that of untransfected HCT116 cells and HCT GCctl cells (Fig. 4B), indicating that the loss of the $140 \mathrm{kDa}$ isoform alone is insufficient to cause a reduction in intercellular adhesion.

The effect of the loss of intercellular adhesion (an EMT feature) on cell motility was examined using wound healing assays. Cells cultured to confluency were artificially wounded by scratching a pipette tip across the monolayer and analyzed for up to $24 \mathrm{~h}$. The wound fronts of HCT116 cells treated with RNAi targeted to both palladin isoforms (RNAi \#2 and HCT RNAi \#3) resembled that of E1 cells, having a spindleshaped/mesenchymal morphology with a reduction in intercellular adhesion and contact inhibition. Single cells extending out of the wound front were also observed (Fig. 4C). This contrasted with the wound fronts of HCT116 treated with RNAi specifically targeted towards the $140 \mathrm{kDa}$ isoform (HCT RNAi \#1), as well as HCT116 treated with control RNAi (HCT GCctl) and untransfected HCT116, which exhibited epithelial morphology with preservation of intercellular adhesion (Fig. 4C). Cell movements during the wound healing process of E1, HCT GCctl and HCT RNAi \#2 cells were also captured for $18 \mathrm{~h}$ using time-lapse microscopy. HCT GCctl cells exhibited directional, collective migration as an epithelial sheet with intercellular adhesion. Cells remained attached throughout, with none detaching to migrate independently (data not shown). This organized cell sheet migration was absent in E1 cells. Instead, the spindleshaped elongated cells moved independently of their neighbours rather than as a cohesive unit. Individual cells were also observed to extend out of the wound-front (data not shown). HCT RNAi \#2 cells exhibited a loss of organized cell sheet migration and intercellular adhesion, with individual cells moving away from the wound front, resembling the migration pattern of E1 cells. Knockdown of both the palladin isoforms also resulted in cells that have a spindle-like morphology, although these cells were not as elongated as the E1 cells (data not shown). The rate of wound healing (i.e., rate of cell motility) was also calculated by measuring the distances of the wound covered by the respective cells at the end of $24 \mathrm{~h}$ (using the still images captured at 0 and $24 \mathrm{~h}$ 
A

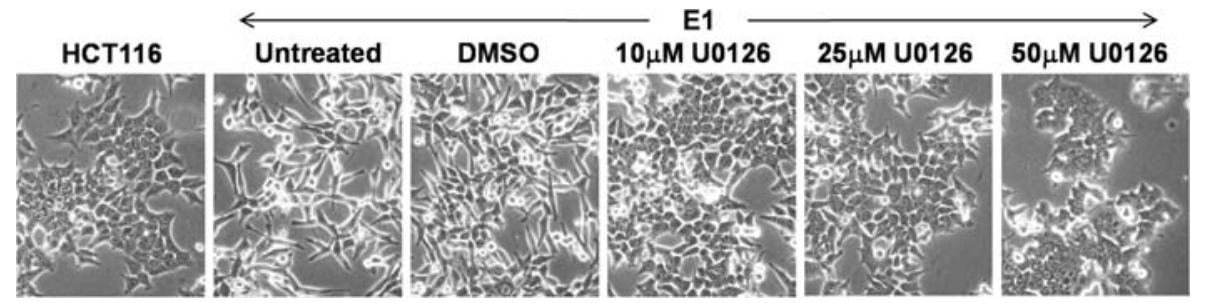

B

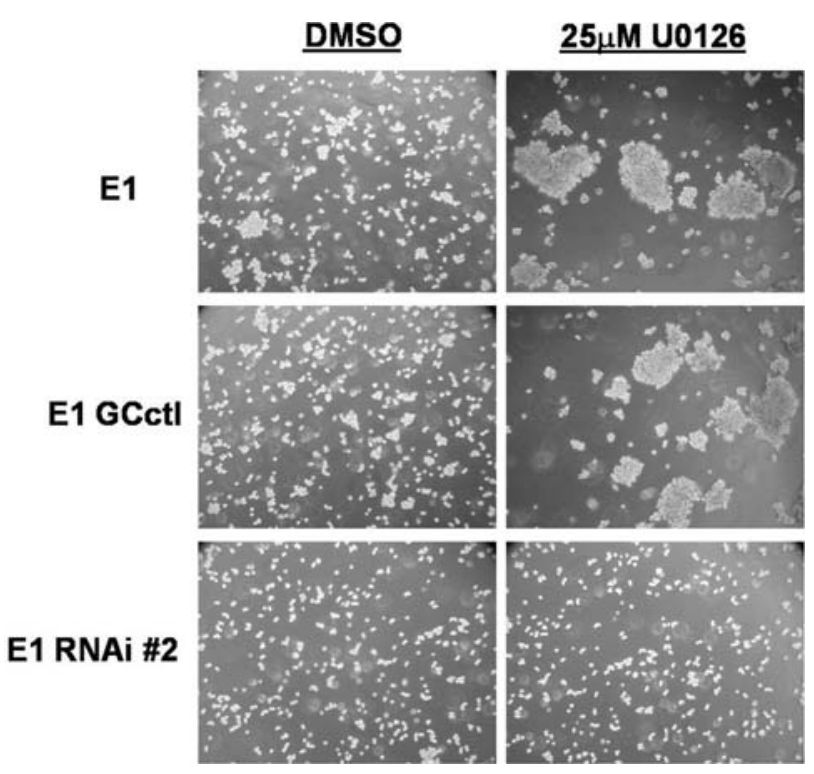

C(a)

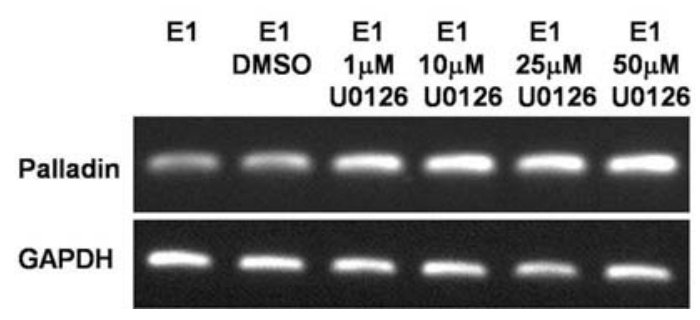

C(b)

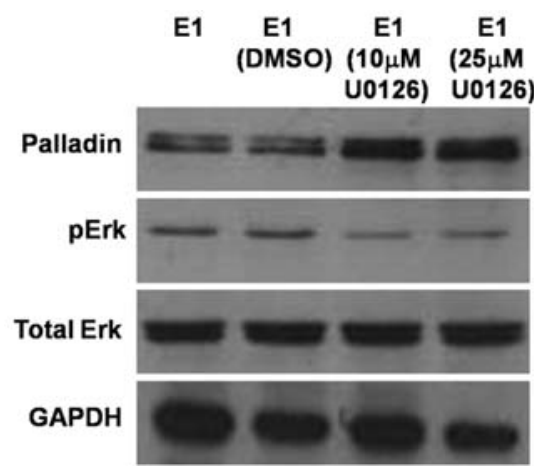

D

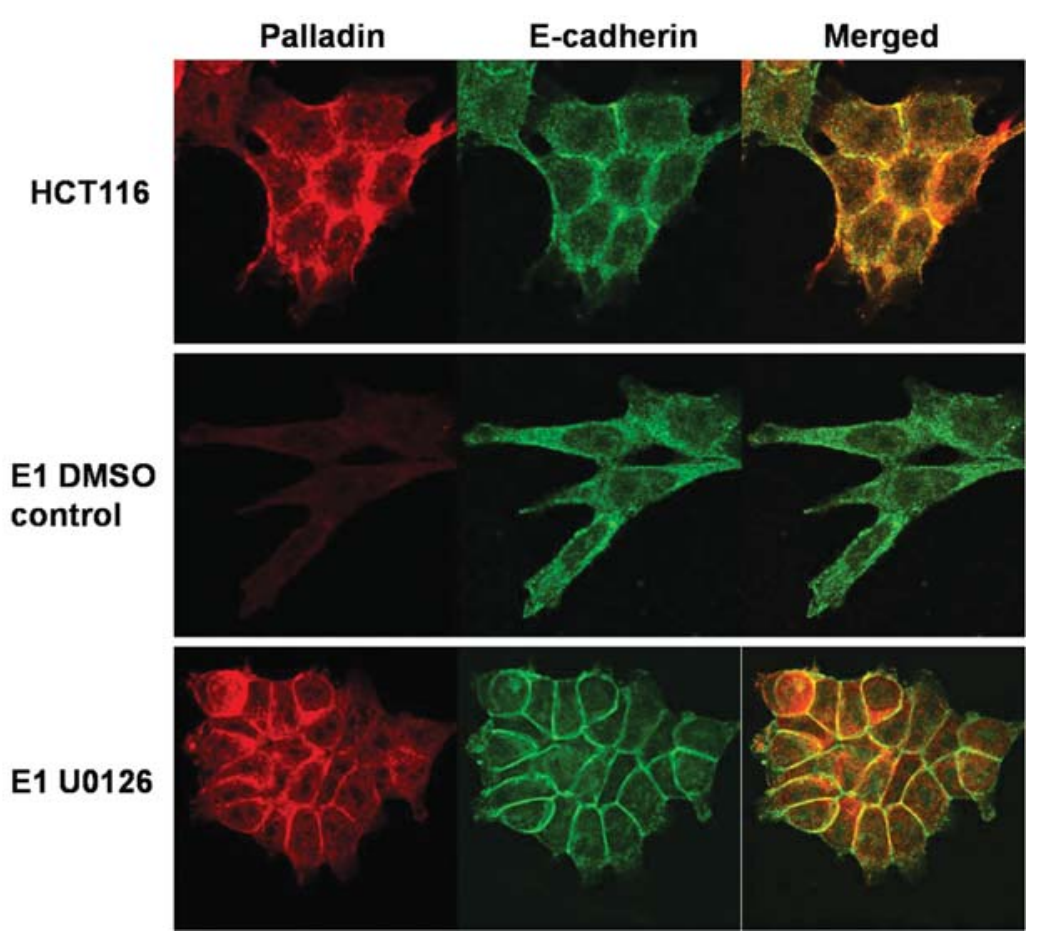

Figure 6. Effects of the inhibition of the Mek/Erk pathway on the morphology of E1 cells and the expression and localization of palladin. A, Phase-contrast microscopy showing the morphology of: HCT116 cells, untreated E1 cells, or E1 cells treated with DMSO (control), 10,25 or $50 \mu \mathrm{M}$ of U0126. B, Suspension cultures of: E1 cells treated with DMSO or $25 \mu \mathrm{M}$ of U0126 (top panel); E1 cells transfected with control RNAi (middle panel) or RNAi \#2 (bottom panel), followed by treatment with DMSO (left column) or $25 \mu \mathrm{M}$ of U0126 (right column). All cells were treated with DMSO or U0126 for $24 \mathrm{~h}$ before re-seeding into low cluster plates. Cells were cultured in suspension for $24 \mathrm{~h}$ in the tissue culture incubator, after which images were taken with a camera attached to the Zeiss Axiovert microscope equipped with a x10 phase-contrast objective. C, Palladin mRNA and protein expression in untreated E1 cells, E1 cells treated with DMSO or U0126 for $24 \mathrm{~h}$ was studied using RT-PCR (a) and Western blot analysis (b), respectively. The expression of phosphorylated Erk (pErk) and total Erk in untreated E1 cells and E1 cells treated with DMSO or U0126 for $24 \mathrm{~h}$ was studied by Western blot analysis (b). Erk inhibition changed levels of pErk but not total Erk. GAPDH was used as a loading control. D, Confocal microscopy images of HCT116 cells, E1 cells treated with DMSO or $25 \mu \mathrm{M}$ U126 for 24 h, fluorescently stained with palladin and E-cadherin antibodies. 
$\mathbf{E}$

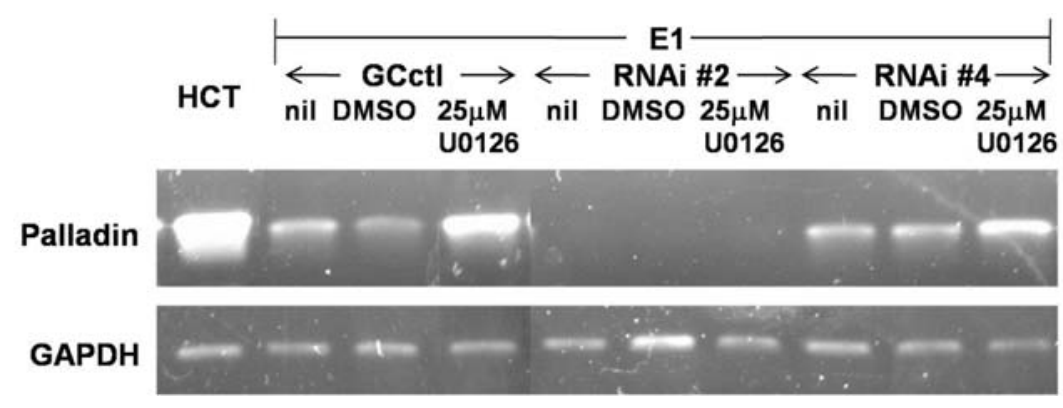

F

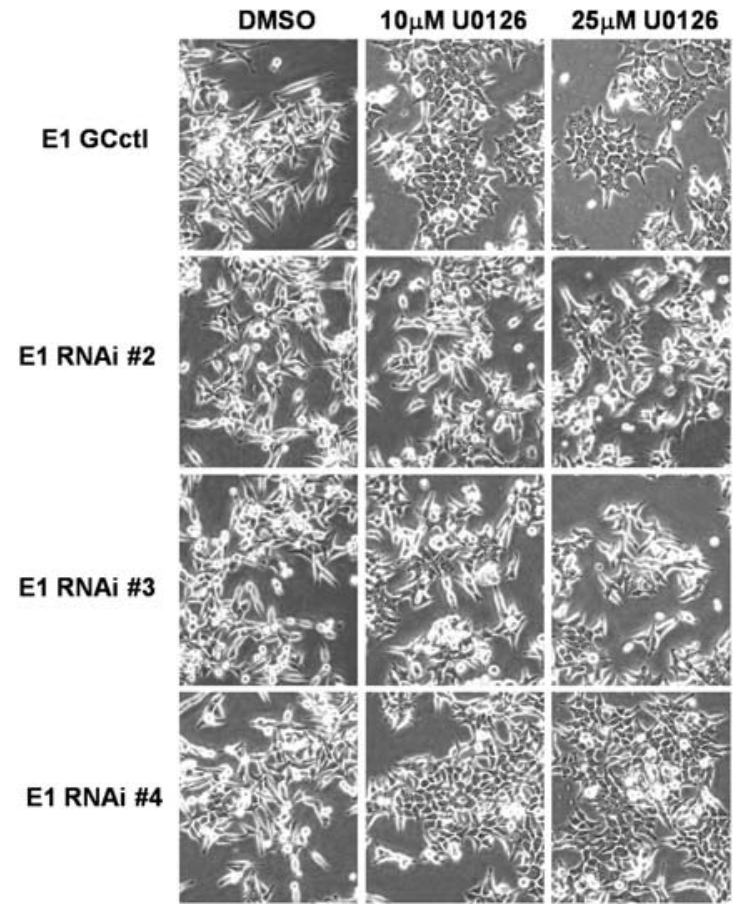

post-wounding). However, there were no significant changes in the rate of wound healing between the HCT116 cells and HCT116 cells transfected with respective RNAi (data not shown).

Thus, whilst a knockdown of both palladin isoforms in HCT116 cells did not significantly increase the rate of wound healing, a distinct change in the cell motility pattern was observed. The organized epithelial cell sheet migration in palladin knockdown cells was lost and there was also a reduction/loss of intercellular adhesion. The dysregulation of these two important features of EMT suggests that palladin has a role in EMT in the transformation of HCT116 cells to E1 cells.

Knockdown of palladin suppresses the junctional localization of E-cadherin without a change in total E-cadherin expression. The expression and localization of palladin were studied in HCT116 and E1 cells by immunofluorescence confocal microscopy. Palladin was localized to focal adhesions and spike-like filopodia structures (Fig. 5A, plane 1) and enriched at adherens junctions in HCT116 cells (Fig. 5A, plane 2). E1 cells showed a general reduction in staining with non-specific localization of palladin (Fig. 5A). Moreover, coimmunofluorescence staining showed a partial co-localization between palladin and adherens junction proteins (e.g., E-cadherin and $\alpha$-actinin) in HCT116 cells (Fig. 5B). Co-
Figure 6. Continued. E, RT-PCR analysis of palladin mRNA expression in HCT116 cells, E1 cells transfected with control RNAi or RNAi \#2, followed by no treatment, or treatment with DMSO, 10 or $25 \mu \mathrm{M}$ of U0126. Cells were treated with DMSO or U0126 for $24 \mathrm{~h}$, at $24 \mathrm{~h}$ post-transfection. GAPDH was used as loading control. F, E1 cells transfected with control RNAi (GCctl), RNAi \#2, \#3 or \#4, followed by treatment with DMSO, 10 or $25 \mu \mathrm{M}$ of U0126. E1 cells were treated with DMSO or U0126 for $24 \mathrm{~h}$. For RNAitransfected E1 cells, DMSO or U0126 was added at $24 \mathrm{~h}$ post-transfection.

immunoprecipitation analysis further confirmed a physical association between palladin and $\alpha$-actinin in HCT116 cells (Fig. 5C), consistent with observations in other cell lines (47). No physical interaction between palladin and other major adherens junction proteins (E-cadherin, $\alpha$-catenin, $ß$-catenin and p120-catenin) was found in HCT116 cells using the co-immunoprecipitation assay (data not shown). These observations together suggest that palladin might physically associate with adherens junction protein complex via $\alpha$-actinin in HCT116 cells.

As the knockdown of palladin affected the intercellular adhesion in HCT116 cells, we examined the effects of palladin down-regulation on E-cadherin localization and expression. The pattern of palladin and E-cadherin expression was unchanged in cells transfected with the control RNAi (HCT GCctl). Palladin was enriched at the adherens junctions, partially co-localized with E-cadherin and showed a more punctuate staining pattern compared to the more continuous staining pattern of E-cadherin (Fig. 5D). On the other hand, cells transfected with palladin RNAi \#2 (HCT RNAi \#2) exhibited diminished palladin staining associated with a decrease in E-cadherin localization at the adherens junctions. E-cadherin was localized to the cytoplasm/nucleus of these cells (Fig. 5D). The loss of palladin expression in the HCT RNAi \#2 cells did not affect total E-cadherin expression (Fig. 5E), but changed its localization. Thus, we have established a novel link between palladin expression and the adherens junction protein complex in HCT116 cells whereby, a down-regulation of palladin caused a loss of junctional E-cadherin localization without a loss of E-cadherin expression.

The expression and localization of palladin to the adherens junction can be restored by inhibition of the Mek/Erk pathway. Multiple signaling pathways and effectors contribute to EMT. The TGFß pathway and the Erk pathway downstream of receptor tyrosine kinases are examples of common signaling pathways involved in EMT (12). E1 cells treated with U0126, a chemical inhibitor of the Mek/Erk pathway, exhibited a reversion of its mesenchymal phenotype to an epithelial morphology resembling parental HCT116 cells (Fig. 6A). This was associated with a restitution of intercellular adhesion. E1 
cells treated with $25 \mu \mathrm{M}$ of U0126 (E1 U0126) formed large spheroids that were similar to those formed by the HCT116 cells (Fig. 4B) whereas DMSO treated cells retained a scattered single cell/small aggregation morphology (Fig. 6B) like that of untreated E1 (Fig. 4B). Associated with the changes in cell morphology and aggregation patterns, the inhibition of the Erk pathway in E1 cells caused an increase in palladin mRNA (RT-PCR) and the $90 \mathrm{kDa}$ palladin isoform protein (Western blot analysis) expression (Fig. 6C). The palladin protein was correctly localized to adherens junctions as shown in the bottom panel of Fig. 6D. The staining patterns of both palladin and E-cadherin are indistinguishable between HCT116 cells and E1 cells treated with U0126.

To determine whether the reversion of E1 cells to an epithelial phenotype after U0126 treatment was dependent on palladin, we transfected E1 cells with control RNAi, palladin RNAi \#2,\#3 or \#4 (E1 GCctl, E1 RNAi \#2, E1 RNAi \#3, E1 RNAi \#4, respectively), before treating them with 10 or $25 \mu \mathrm{M}$ U0126. The efficacy of preventing the up-regulation of palladin after U0126 treatment is shown in Fig. 6E. E1 cells transfected with control RNAi or RNAi \#4 (which knocks down only the $140 \mathrm{kDa}$ isoform) responded to U0126 treatment with a reversion of mesenchymal morphology to an epithelial morphology. However, cells transfected with either RNAi \#2 or \#3 did not respond to U0126 treatment and remained mesenchymal (Fig. 6F). Similarly, the reversion of the E1 cells to a more aggregated morphology after U0126 treatment was also prevented by prior treatment of the cells with RNAi \#2 but not the control RNAi (Fig. 6B). These results indicate that the morphological changes associated with U0126 treatment are dependent on the induction of the $90 \mathrm{kDa}$ palladin isoform and suggests that palladin is an integral component in the Erk signaling pathway regulating EMT in these cells.

Palladin is strongly expressed at the adherens junctions and cytoplasm in well-differentiated tumor tubules and downregulated in poorly-differentiated tumor tubules and dissociated tumor cells. Immunohistochemical analysis of palladin expression was carried out on formalin-fixed paraffinembedded tissues of 18 matched normal colonic mucosa and colorectal tumors obtained from the National University of Singapore, Department of Pathology. Most of the adenocarcinomas were classified as having a moderately differentiated phenotype, except for 3 cases which were moderately to poorly-differentiated. Palladin was expressed at the adherens junctions and cytoplasm of normal colonic epithelia. Expression was stronger at the well-differentiated surface epithelium (Fig. 7A, middle panel) compared to cells at the crypt (Fig. 7A, right panel). Although the tumor samples were broadly classified as moderately or poorly-differentiated, there was a heterogenous mix of well to poorly-differentiated tubular areas within a sample. Interestingly, palladin expression appeared to be directly correlated to tubular differentiation. The better differentiated tubular structures showed stronger palladin staining that was localized to both adherens junctions and the cytoplasm (Fig. 7B, panels a, b), similar in pattern to that observed in adjacent normal mucosa (Fig. 7B, panel c). Palladin expression was down-regulated in tubules at the invasive front (Fig. 7B, panel d) where expression was predominantly cytoplasmic, with reduced or absent adherens junction expression (Fig. 7B, panels e, f). Palladin expression was most down-regulated in cell clusters and individual cells that have dissociated from the tumor tubules at the invasive front (Fig. 7C, panels a-d). Hence, the overall pattern of palladin expression appears to be correlated to tubular differentiation within the tumor sample. The better differentiated, intact tubules expressed higher levels of palladin, which is often localized at the adherens junctions and cytoplasm. Poorly-differentiated tubules and detached cell clusters and individual cells expressed low levels of palladin which is localized to the cytoplasm rather than adherens junctions. The pattern of expression and localization of palladin in primary tumors and adjacent normal tissue is consistent with its role in intercellular adhesion. The loss of palladin may be associated with the dedifferentiation of cells to a more mesenchymal phenotype and a necessary step to facilitate tumor invasion into surrounding tissues.

\section{Discussion}

Palladin is an actin cross-linking protein that also acts as a scaffold for multiple actin-binding proteins such as ezrin, VASP/Mena/EVL, profilin, $\alpha$-actinin, Lasp-1 and Eps8 $(15,16$, 47-50) and signaling proteins such as ArgBP-2, SPIN-90 and Src $(51,52)$. Palladin is commonly localized along stress fibers, dorsal ruffles and podosomes $(14,48)$ where it is required in the assembly and maintenance of actin-dependent structures (13). Both knockdown and overexpression of palladin resulted in gross reorganization of the actin cytoskeleton. When palladin expression was down-regulated in fibroblasts using antisense approaches, stress fibers and focal adhesions were lost and the cells rounded up (14). Similarly, overexpression of palladin in Cos7 cells and astrocytes led to an increase in the number and size of actin bundles $(15,53)$. Studies in cultured cells and knockout mice further showed the involvement of palladin in cell motility, which was related to its actinorganizing activities $(13,54,55)$.

Although there is an earlier study showing palladin localization at adherens junctions of chick pigmented epithelium (14), most of the studies on palladin have focused on its role in actin organization and cell motility rather than on intercellular adhesion. Our results establish a novel link between palladin expression and E-cadherin localization at adherens junctions in HCT116 cells. It appears that palladin is required for the proper localization of E-cadherin to adherens junctions and hence, the establishment and stabilization of these intercellular junctions amongst HCT116 cells. This is an important function, especially in the context of tumorigenesis, because a loss of E-cadherin on the cell surface has been shown to play a role in tumor progression and metastasis (23). Our data show that disruption of cell adherens junction in HCT116 cells is not necessarily due to a loss of E-cadherin expression but may be caused by a loss of E-cadherin localization to the cell junctions. E-cadherin interacts with other key cytoskeletal components such as actin, $\alpha$-actinin, vinculin and $\alpha$-catenin at the junctions. A disruption of these interactions may lead to a destabilization of adherens junctions and a cytoplasmic rather than junctional localization of E-cadherin. For example, a reduced expression of $\alpha$-catenin (which mediates connection of the E-cadherin/catenin complex to 
A
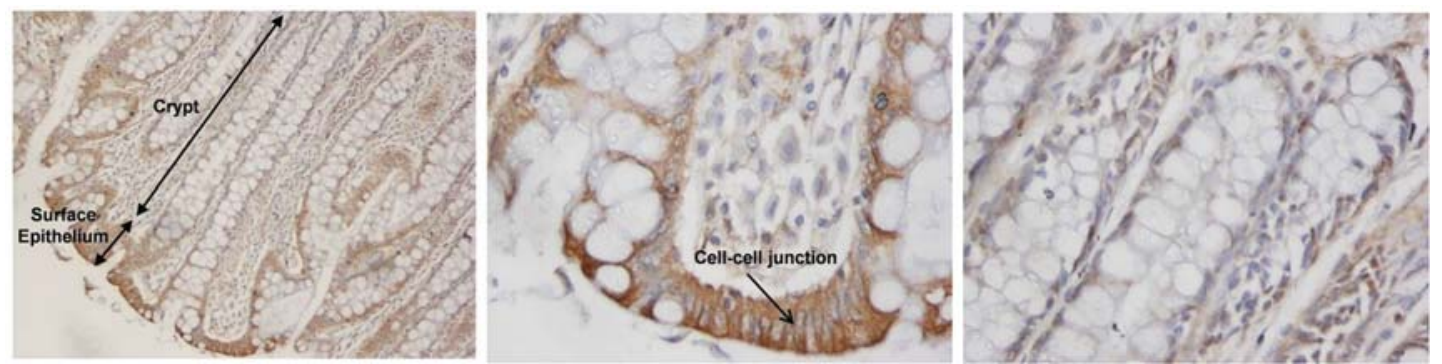

$\mathbf{B}$
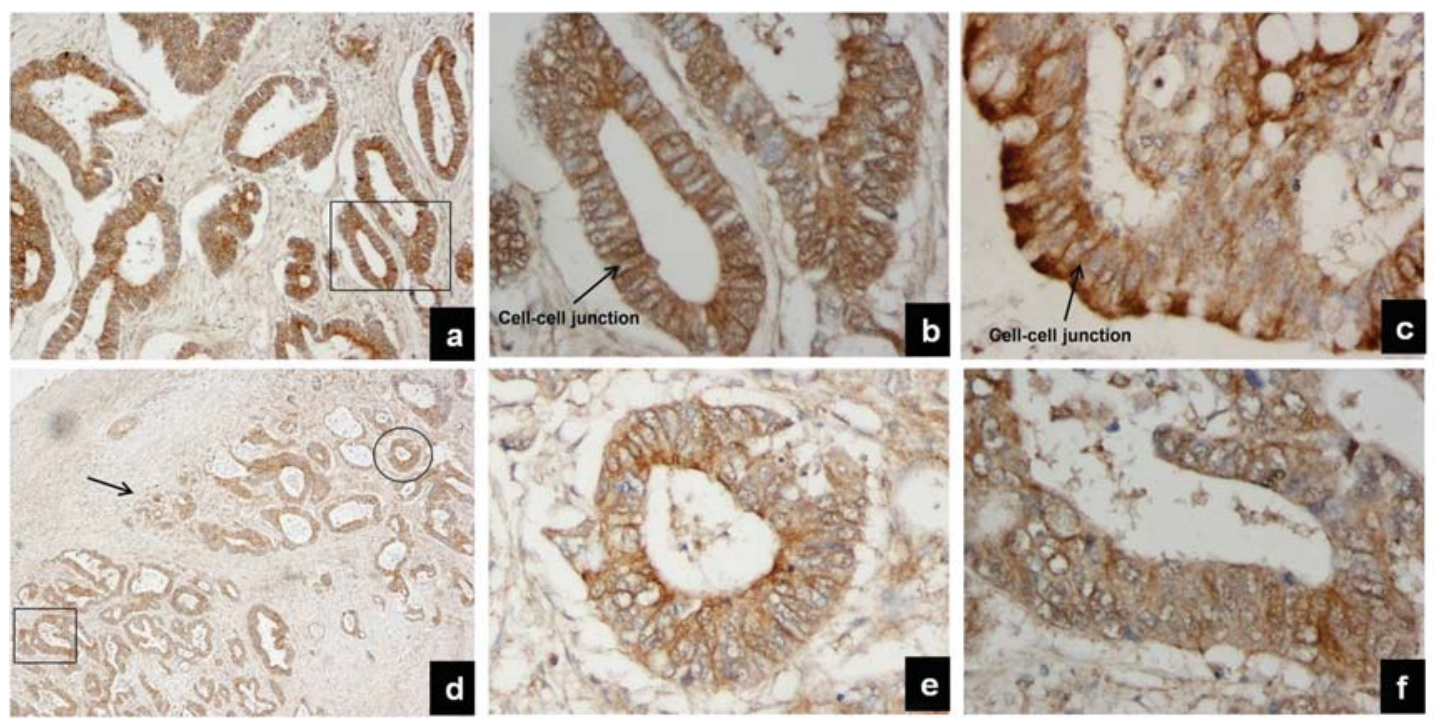

C
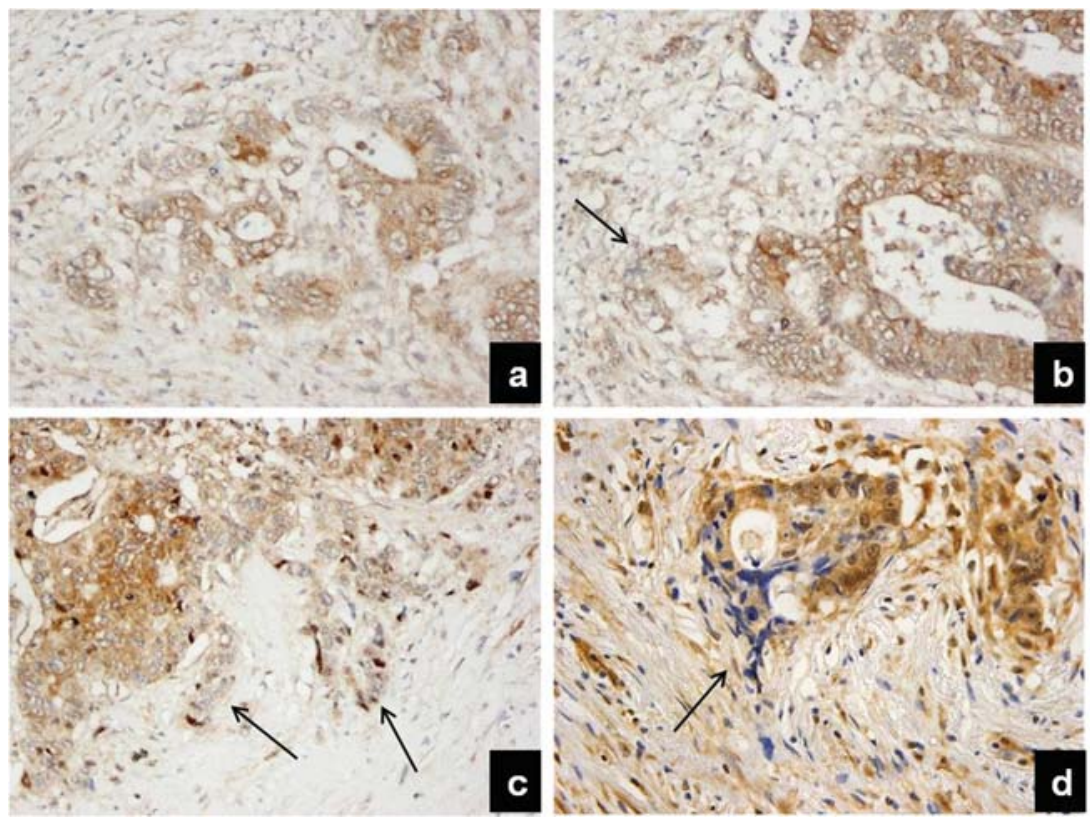

Figure 7. Immunohistochemical analysis of palladin expression in matched normal colonic mucosa and colorectal tumors tissue sections. A, Immunohistochemical staining of palladin in the surface epithelium and crypt of normal colonic mucosa (left panel) (x100 magnification). A further magnified section of the surface epithelium (middle panel) (x400), and the crypt (right panel) (x400). B, Colorectal tumor section showing palladin staining at the central tumor area (a) and at the invasive front (d). The central tumor area has intact well-differentiated tubules, (b) (x400) shows the magnified section of the boxed region in (a) (x100). The palladin staining in central tumor area was compared to that of matched normal colonic mucosa (c) (x400). Region of the invasive front was shown in (d) (x40). The circled and boxed regions showed the moderately-/poorly-differentiated tumor tubules, which are respectively enlarged in (e) (x400) and (f) (x400). Cells that have dissociated from the tumor tubules at the invasive front are indicated by the arrow and boxed region in (d) and shown enlarged in C(a) (x200) and (b) (x200), respectively. C, Representative examples of palladin expression of de-differentiated tumor areas (indicated by arrows) in the invasive fronts of colorectal tumor sections, which could exhibit as dissociated cells that form small clusters (a), (b), (c) (x200), or isolated tumor cells (d) (x400). Brown staining indicates positive palladin staining, blue hematoxylin was used as the counterstain. 
actin cytoskeleton), has been frequently reported in colorectal cancers and may result in the cytoplasmic relocation of E-cadherin (56). How a loss of palladin expression leads to the disruption of adherens junctions in HCT116 cells is unclear. Since we have validated that palladin can interact directly with $\alpha$-actinin in HCT116 cells, one possibility is that palladin is required for the stabilization of the adherens junction protein complex to the actin cytoskeleton. $\alpha$-actinin links the E-cadherin-catenin complex to the actin cytoskeleton through its interaction with $\alpha$-catenin (57). It is possible that $\alpha$-actinin might require palladin to stabilize the E-cadherin complex to the actin cytoskeleton in HCT116 cells . Alternatively, since palladin is also an actin cross-linking protein that acts as a scaffold for multiple actin-binding proteins and signaling molecules, the loss of palladin may perturb actin dynamics which may in turn affect the formation and stabilization of adherens junctions. Down-regulation of Dia1 (58) and cortactin (59) both of which are involved in actin polymerization has previously been shown to be involved in the development and maintenance of adherens junctions.

Our study also highlights the importance of the Erk signaling pathway in the regulation of adherens junctions, cell morphology and palladin expression. The inhibition of this signaling pathway caused a complete reversion of the E1 mesenchymal to the parental HCT116 epithelial phenotype. Associated with this reversion, adherens junctions were reformed and palladin expression was restored in E1 cells. We also showed that palladin was required for the reversion to an epithelial phenotype. Knockdown of palladin expression using palladin specific siRNA abrogated the reversion induced by Erk inhibitor treatment, suggesting that palladin is required for the formation of adherens junctions in E1 cells. Hence, palladin expression is regulated by the Erk signaling pathway and its regulation mediates at least in part the effect of this pathway on adherens junction formation and cell morphology in E1 cells.

The loss of palladin and consequent disruption of adherens junction may have effects other than a change in morphology from an epithelial to a mesenchymal phenotype. The disruption of the E-cadherin/catenin complex releases $\beta$-catenin from the membranous pool, increasing its cytoplasmic pool. When not rapidly degraded, $\beta$-catenin can translocate into the nucleus to transactivate genes involved in tumor progression (60). Consistent with this hypothesis, some of the target genes of the B-catenin/TCF pathway such as BMP4, Sox9, Jag1 and Fn were up-regulated in the metastatic E1 cell line in our microarray study.

Our study shows a down-regulation of palladin in the more metastatic human colon cancer cell line E1 as well as in poorly-differentiated tumor tubules or dissociated tumor cells in primary colon tumors. We hypothesize that the downregulation of palladin occurs early in the metastatic cascade, allowing cells to detach from the tumor mass and invade into the stroma. There are few studies on the expression of palladin in cancers. Palladin was found to be up-regulated in invasive cells compared with non-motile cells in a mouse xenograft tumor model where human breast tumor cells were induced to migrate using growth factors (61). A recent study showed that palladin levels in breast cancer patients are higher in malignant tissues than in normal breast samples. The authors also showed that palladin expression was higher in the more invasive breast cancer cell lines, where it was thought to play a role in podosome (matrix-degrading structures) formation (62). Serial analysis of gene expression (SAGE) of pancreatic and colorectal cancers at invasive sites, comprising both epithelial and stromal elements, identified palladin to be within a cluster of invasion-specific genes (63). However, in a separate report by Salaria et al, it was found that palladin expression levels were comparable between pancreatic cancer cells and non-neoplastic pancreatic cells, with high expression levels predominantly seen in non-neoplastic stromal fibroblasts of pancreatic tumor sections (64). These previous reports showing an up-regulation of palladin with increased invasion is invariant to our observation that loss in palladin expression is associated with increased invasiveness in colon rectal cancer. It is possible that there are tumor specific differences in the role and regulation of palladin in different cancers. Alternatively, it may also be possible that palladin is regulated differently at different stages of the metastatic cascade. For example, it may be down-regulated early on to allow cells to detach, but up-regulated later to allow cells to colonize the metastatic site.

In summary, the study has provided evidence for the involvement of palladin in adherens junction formation of epithelial colorectal cancer cell line HCT116 and demonstrated a link between palladin and the Erk signaling pathway in regulating the transition of cells from an epithelial to mesenchymal phenotype. Given the significance of these processes in cancer progression, it will be important to better define the role of palladin in these processes.

\section{Acknowledgements}

This study was funded by National University of Singapore Academic Research Fund Grant (ARF/R-185-000-074-112, Shing Chuan Hooi), and National Medical Research Council (NMRC/EDG/0003/2007, Shing Chuan Hooi).

\section{References}

1. Parkin DM, Bray F, Ferlay J and Pisani P: Global cancer statistics, 2002. CA Cancer J Clin 55: 74-108, 2005.

2. Markowitz SD, Dawson DM, Willis J and Willson JK: Focus on colon cancer. Cancer Cell 1: 233-236, 2002.

3. Chambers AF, Groom AC and MacDonald IC: Dissemination and growth of cancer cells in metastatic sites. Nat Rev Cancer 2: 563-572, 2002.

4. Fidler IJ: The pathogenesis of cancer metastasis: the 'seed and soil' hypothesis revisited. Nat Rev Cancer 3: 453-458, 2003.

5. Shih W, Chetty R and Tsao MS: Expression profiling by microarrays in colorectal cancer (Review). Oncol Rep 13: 517-524, 2005.

6. Thiery JP: Epithelial-mesenchymal transitions in tumour progression. Nat Rev Cancer 2: 442-454, 2002.

7. Brabletz T, Jung A, Spaderna S, Hlubek F and Kirchner T: Opinion: Migrating cancer stem cells - an integrated concept of malignant tumour progression. Nat Rev Cancer 5: 744-749, 2005.

8. Berx G, Raspe E, Christofori G, Thiery JP and Sleeman JP: Preemting metastasis? Recapitulation of morphogenetic processes in cancer. Clin Exp Metastasis 24: 587-597, 2007.

9. Clark EA, Golub TR, Lander ES and Hynes RO: Genomic analysis of metastasis reveals an essential role for RhoC. Nature 406: 532-535, 2000.

10. Kang Y, Siegel PM, Shu W, et al: A multigenic program mediating breast cancer metastasis to bone. Cancer Cell 3: 537-549, 2003. 
11. Yang J, Mani SA, Donaher JL, et al: Twist, a master regulator of morphogenesis, plays an essential role in tumor metastasis. Cell 117: 927-939, 2004.

12. Thiery JP and Sleeman JP: Complex networks orchestrate epithelial-mesenchymal transitions. Nat Rev Mol Cell Biol 7: 131-142, 2006

13. Goicoechea SM, Arneman D and Otey CA: The role of palladin in actin organization and cell motility. Eur J Cell Biol 87: 517-525, 2008

14. Parast MM and Otey CA: Characterization of palladin, a novel protein localized to stress fibers and cell adhesions. J Cell Biol 150: 643-656, 2000

15. Rachlin AS and Otey CA: Identification of palladin isoforms and characterization of an isoform-specific interaction between Lasp-1 and palladin. J Cell Sci 119: 995-1004, 2006.

16. Goicoechea S, Arneman D, Disanza A, Garcia-Mata R, Scita G and Otey CA: Palladin binds to Eps8 and enhances the formation of dorsal ruffles and podosomes in vascular smooth muscle cells. J Cell Sci 119: 3316-3324, 2006.

17. Bershadsky A: Magic touch: how does cell-cell adhesion trigger actin assembly? Trends Cell Biol 14: 589-593, 2004.

18. Morikawa K, Walker SM, Jessup JM and Fidler IJ: In vivo selection of highly metastatic cells from surgical specimens of different primary human colon carcinomas implanted into nude mice. Cancer Res 48: 1943-1948, 1988.

19. Martin-Blanco E and Knust E: Epithelial morphogenesis: filopodia at work. Curr Biol 11: R28-R31, 2001.

20. Huber MA, Kraut $\mathrm{N}$ and Beug $\mathrm{H}$ : Molecular requirements for epithelial-mesenchymal transition during tumor progression. Curr Opin Cell Biol 17: 548-558, 2005.

21. Robson EJ, Khaled WT, Abell K and Watson CJ: Epithelial-tomesenchymal transition confers resistance to apoptosis in three murine mammary epithelial cell lines. Differentiation 74 : 254-264, 2006

22. Grunert S, Jechlinger $M$ and Beug H: Diverse cellular and molecular mechanisms contribute to epithelial plasticity and metastasis. Nat Rev Mol Cell Biol 4: 657-665, 2003.

23. Buda A and Pignatelli M: Cytoskeletal network in colon cancer: from genes to clinical application. Int J Biochem Cell Biol 36: 759-765, 2004

24. Lipponen P, Saarelainen E, Ji H, Aaltomaa S and Syrjanen K: Expression of E-cadherin (E-CD) as related to other prognostic factors and survival in breast cancer. J Pathol 174: 101-109, 1994.

25. Gabbert HE, Mueller W, Schneiders A, et al: Prognostic value of E-cadherin expression in 413 gastric carcinomas. Int J Cancer 69: 184-189, 1996

26. Nieman MT, Prudoff RS, Johnson KR and Wheelock MJ: $\mathrm{N}$-cadherin promotes motility in human breast cancer cells regardless of their E-cadherin expression. J Cell Biol 147: 631-644, 1999

27. Kartenbeck J, Haselmann U and Gassler N: Synthesis of junctional proteins in metastasizing colon cancer cells. Eur J Cell Biol 84: 417-430, 2005.

28. Lee JM, Dedhar S, Kalluri R and Thompson EW: The epithelialmesenchymal transition: new insights in signaling, development, and disease. J Cell Biol 172: 973-981, 2006.

29. Christiansen JJ and Rajasekaran AK: Reassessing epithelial to mesenchymal transition as a prerequisite for carcinoma invasion and metastasis. Cancer Res 66: 8319-8326, 2006.

30. Garrett SC, Varney KM, Weber DJ and Bresnick AR: S100A4, a mediator of metastasis. J Biol Chem 281: 677-680, 2006.

31. Montel V, Huang TY, Mose E, Pestonjamasp K and Tarin D: Expression profiling of primary tumors and matched lymphatic and lung metastases in a xenogeneic breast cancer model. Am J Pathol 166: 1565-1579, 2005.

32. Steeg PS: New insights into the tumor metastatic process revealed by gene expression profiling. Am J Pathol 166: 1291-1294, 2005

33. Weichert W, Denkert C, Burkhardt M, et al: Cytoplasmic CD24 expression in colorectal cancer independently correlates with shortened patient survival. Clin Cancer Res 11: 6574-6581, 2005 .

34. Han HJ, Russo J, Kohwi Y and Kohwi-Shigematsu T: SATB1 reprogrammes gene expression to promote breast tumour growth and metastasis. Nature 452: 187-193, 2008.

35. Steventon B, Carmona-Fontaine C and Mayor R: Genetic network during neural crest induction: from cell specification to cell survival. Semin Cell Dev Biol 16: 647-654, 2005.
36. Sakai D, Suzuki T, Osumi N and Wakamatsu Y: Cooperative action of Sox9, Snail2 and PKA signaling in early neural crest development. Development 133: 1323-1333, 2006.

37. Zavadil J, Cermak L, Soto-Nieves N and Bottinger EP: Integration of TGF-beta/Smad and Jagged1/Notch signalling in epithelial-to-mesenchymal transition. EMBO J 23: 1155-1165, 2004.

38. Okada H, Danoff TM, Kalluri R and Neilson EG: Early role of Fsp1 in epithelial-mesenchymal transformation. Am J Physiol 273: F563-F574, 1997

39. Xue C, Plieth D, Venkov C, Xu C and Neilson EG: The gatekeeper effect of epithelial-mesenchymal transition regulates the frequency of breast cancer metastasis. Cancer Res 63: 3386-3394, 2003.

40. Roof DJ, Hayes A, Adamian M, Chishti AH and Li T: Molecular characterization of abLIM, a novel actin-binding and double zinc finger protein. J Cell Biol 138: 575-588, 1997.

41. Wakabayashi M, Ito T, Mitsushima M, et al: Interaction of lp-dlg/KIAA0583, a membrane-associated guanylate kinase family protein, with vinexin and beta-catenin at sites of cell-cell contact. J Biol Chem 278: 21709-21714, 2003.

42. Dawid IB, Breen JJ and Toyama R: LIM domains: multiple roles as adapters and functional modifiers in protein interactions. Trends Genet 14: 156-162, 1998.

43. Fanning AS and Anderson JM: PDZ domains: fundamental building blocks in the organization of protein complexes at the plasma membrane. J Clin Invest 103: 767-772, 1999.

44. Schaapveld RQ, Borradori L, Geerts D, et al: Hemidesmosome formation is initiated by the beta4 integrin subunit, requires complex formation of beta4 and HD1/plectin, and involves a direct interaction between beta4 and the bullous pemphigoid antigen 180. J Cell Biol 142: 271-284, 1998.

45. Koster J, van Wilpe S, Kuikman I, Litjens SH and Sonnenberg A: Role of binding of plectin to the integrin beta4 subunit in the assembly of hemidesmosomes. Mol Biol Cell 15: 1211-1223, 2004.

46. Weber KL, Fischer RS and Fowler VM: Tmod3 regulates polarized epithelial cell morphology. J Cell Sci 120: 3625-3632, 2007.

47. Ronty M, Taivainen A, Moza M, Otey CA and Carpen O: Molecular analysis of the interaction between palladin and alpha-actinin. FEBS Lett 566: 30-34, 2004.

48. Mykkanen OM, Gronholm M, Ronty M, et al: Characterization of human palladin, a microfilament-associated protein. Mol Biol Cell 12: 3060-3073, 2001

49. Boukhelifa M, Parast MM, Bear JE, Gertler FB and Otey CA: Palladin is a novel binding partner for Ena/VASP family members. Cell Motil Cytoskeleton 58: 17-29, 2004.

50. Boukhelifa M, Moza M, Johansson T, et al: The proline-rich protein palladin is a binding partner for profilin. FEBS Lett 273: 26-33, 2006.

51. Ronty M, Taivainen A, Moza M, Kruh GD, Ehler E and Carpen O: Involvement of palladin and alpha-actinin in targeting of the Abl/Arg kinase adaptor ArgBP2 to the actin cytoskeleton. Exp Cell Res 310: 88-98, 2005.

52. Ronty MJ, Leivonen SK, Hinz B, et al: Isoform-specific regulation of the actin-organizing protein palladin during TGF-beta1induced myofibroblast differentiation. J Invest Dermatol 126: 2387-2396, 2006

53. Boukhelifa M, Hwang SJ, Valtschanoff JG, Meeker RB, Rustioni A and Otey CA: A critical role for palladin in astrocyte morphology and response to injury. Mol Cell Neurosci 23: 661-668, 2003

54. Liu XS, Luo HJ, Yang $\mathrm{H}$, et al: Palladin regulates cell and extracellular matrix interaction through maintaining normal actin cytoskeleton architecture and stabilizing beta1-integrin. J Cell Biochem 100: 1288-1300, 2007.

55. Luo H, Liu X, Wang F, et al: Disruption of palladin results in neural tube closure defects in mice. Mol Cell Neurosci 29: 507-515, 2005

56. Ropponen KM, Eskelinen MJ, Lipponen PK, Alhava EM and Kosma VM: Reduced expression of alpha catenin is associated with poor prognosis in colorectal carcinoma. J Clin Pathol 52: 10-16, 1999.

57. Otey CA and Carpen O: Alpha-actinin revisited: a fresh look at an old player. Cell Motil Cytoskeleton 58: 104-111, 2004.

58. Carramusa L, Ballestrem C, Zilberman Y and Bershadsky AD: Mammalian diaphanous-related formin Dial controls the organization of E-cadherin-mediated cell-cell junctions. J Cell Sci 120: 3870-3882, 2007 
59. Helwani FM, Kovacs EM, Paterson AD, et al: Cortactin is necessary for E-cadherin-mediated contact formation and actin reorganization. J Cell Biol 164: 899-910, 2004.

60. Fuchs SY, Ougolkov AV, Spiegelman VS and Minamoto T: Oncogenic beta-catenin signaling networks in colorectal cancer. Cell Cycle 4: 1522-1539, 2005.

61. Wang W, Goswami S, Lapidus K, et al: Identification and testing of a gene expression signature of invasive carcinoma cells within primary mammary tumors. Cancer Res 64: 85858594, 2004.

62. Goicoechea SM, Bednarski B, Garcia-Mata R, Prentice-Dunn H, Kim HJ and Otey CA: Palladin contributes to invasive motility in human breast cancer cells. Oncogene 28: 587-598, 2009.
63. Ryu B, Jones J, Hollingsworth MA, Hruban RH and Kern SE: Invasion-specific genes in malignancy: serial analysis of gene expression comparisons of primary and passaged cancers. Cancer Res 61: 1833-1838, 2001.

64. Salaria SN, Illei P, Sharma R, et al: Palladin is overexpressed in the non-neoplastic stroma of infiltrating ductal adenocarcinomas of the pancreas, but is only rarely overexpressed in neoplastic cells. Cancer Biol Ther 6: 324-328, 2007. 